Review

\title{
Optimization of Layered Cathode Materials for Lithium-Ion Batteries
}

\author{
Christian Julien ${ }^{1, *}$, Alain Mauger ${ }^{2}$, Karim Zaghib ${ }^{3}$ and Henri Groult ${ }^{1}$ \\ 1 Physicochimie des Electrolytes et Nanosystèmes Interfaciaux (PHENIX), Sorbonne Universités, UPMC Univ. \\ Paris 06, CNRS UMR 8234, 4 place Jussieu, Paris 75005, France; henri.groult@upmc.fr \\ 2 Institut de Minéralogie, de Physique des Matériaux et de Cosmochimie (IMPMC), Sorbonne Universités, \\ UPMC Univ. Paris 06, CNRS UMR 7590, 4 place Jussieu, Paris 75005, France; alain.mauger@impmc.jussieu.fr \\ 3 Institut de Recherche d'Hydro-Québec (IREQ), Stockage and Conversion d'Energie, 1800 Lionel-Boulet, \\ Varennes, QC J3X 1S1, Canada; zaghib.karim@ireq.ca \\ * Correspondence: christian.julien@upmc.fr; Tel.: +33-673-464-084
}

Academic Editor: Deepak Pant

Received: 2 May 2016; Accepted: 15 July 2016; Published: 19 July 2016

\begin{abstract}
This review presents a survey of the literature on recent progress in lithium-ion batteries, with the active sub-micron-sized particles of the positive electrode chosen in the family of lamellar compounds $\mathrm{LiMO}_{2}$, where $M$ stands for a mixture of $\mathrm{Ni}, \mathrm{Mn}$, Co elements, and in the family of $y \mathrm{Li}_{2} \mathrm{MnO}_{3} \bullet(1-y) \mathrm{LiNi}_{\frac{1}{2}} \mathrm{Mn}_{\frac{1}{2}} \mathrm{O}_{2}$ layered-layered integrated materials. The structural, physical, and chemical properties of these cathode elements are reported and discussed as a function of all the synthesis parameters, which include the choice of the precursors and of the chelating agent, and as a function of the relative concentrations of the $M$ cations and composition $y$. Their electrochemical properties are also reported and discussed to determine the optimum compositions in order to obtain the best electrochemical performance while maintaining the structural integrity of the electrode lattice during cycling.
\end{abstract}

Keywords: nanomaterials; layered compounds; cathodes; lithium-ion batteries

\section{Introduction}

Lithium-ion batteries (LiBs) are generally composed of two electrode compounds having an open structure, which act as host frameworks for the insertion/de-insertion of $\mathrm{Li}^{+}$ions and are the place of charge transfer. The $\mathrm{LiB}$ prototype was composed of graphite as a negative electrode (often named anode) and a transition-metal oxide (TMO), i.e., $\mathrm{LiCoO}_{2}, \mathrm{LiMn}_{2} \mathrm{O}_{4}$, etc., as a positive electrode (often named cathode), separated by the electrolyte that provides a transport medium for ions (Figure 1). During the charge of the $\mathrm{LiB}$ charges, the $\mathrm{Li}^{+}$ions are extracted from the cathode and inserted into the anode, while the electrons pass through the outer circuit (load). Consequently, the effectiveness of a lithium-ion cell is dependent on the availability of crystallographic sites for hosting $\mathrm{Li}^{+}$ions, in other words on the insertion mechanism and thereby on the transport properties of ions and electrons in both electrode materials. Note that in the case of LiB with the graphite/TMO configuration, the limiting factor comes from the cathode side [1], in which the redox reaction is described by:

$$
L i \mathrm{M}_{a}^{n} \mathrm{O}_{b} \leftrightarrow L i_{1-x} \mathrm{M}_{a}^{n+x} O_{b}+x L i^{+}+x e^{-}
$$




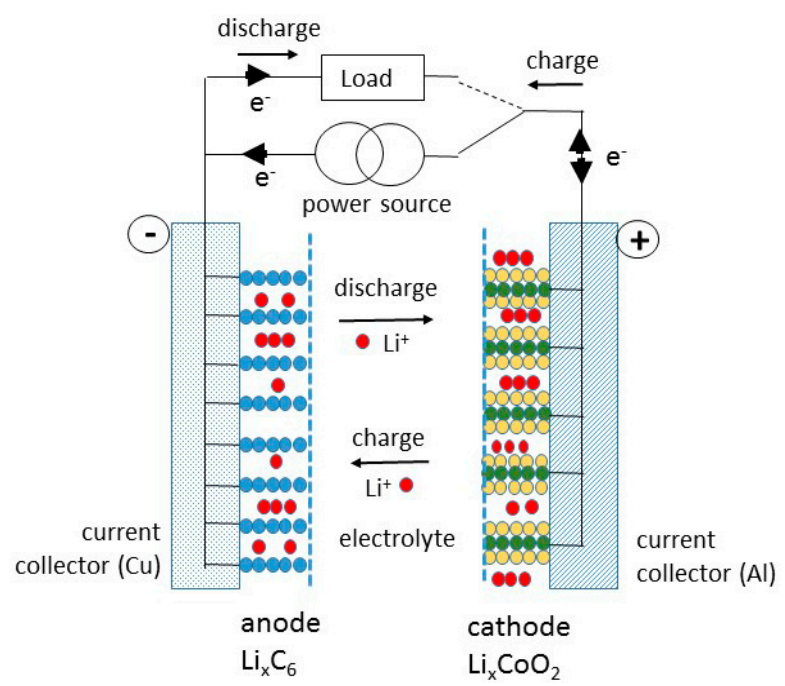

Figure 1. Schematic figure of a Li-ion battery. $\mathrm{LiCoO}_{2}$ is used as a cathode and graphite as an anode.

As the transition metal entering the composition of the active element of the cathode is oxidized and reduced during the cell charge and discharge, respectively (Equation (1)), the cathode is primarily involved in the cathode process and then in the electrochemical performance of the cell, i.e., potential, specific capacity, energy density, rate capability, etc. [2,3].

Conventional rechargeable $\mathrm{Li}$ batteries exhibit rather poor rate performance, even compared with old technologies such as lead-acid [4]. Achieving high rate rechargeable Li-ion batteries depends ultimately on the dimension of the active particles for both negative and positive electrodes [5]. One of the prospective solutions for the preparation of electrodes with high power density is the choice of nanocomposite materials because the geometric design of the insertion compound is a crucial intrinsic property from the viewpoint of structural stability and low kinetics of ions in oxide.

The theoretical capacity of a given electrode material, which influences the C-rate estimations, is calculated by the following equation:

$$
Q_{t h}=\frac{e \times N_{A}}{M_{w} \times 3.6}
$$

where $Q_{\mathrm{th}}$ is the theoretical specific capacity $\left(\mathrm{mAh} \cdot \mathrm{g}^{-1}\right), M_{\mathrm{w}}$ is the mass of the correlated component (g. $\mathrm{mol}^{-1}$ ), and $\mathrm{Z}, \mathrm{N}_{\mathrm{A}}$, and $e$ represent the number of electrons involved in the reaction, Avogadro's number, and electronic charge, respectively. As an example, let us consider the theoretical capacity of the Li-rich layered material $\mathrm{Li}_{1.2} \mathrm{Ni}_{0.2} \mathrm{Mn}_{0.6} \mathrm{O}_{2}$ or $0.5\left(\mathrm{Li}_{2} \mathrm{MnO}_{3}\right) \bullet 0.5\left(\mathrm{LiNi}_{0.5} \mathrm{Mn}_{0.5} \mathrm{O}_{2}\right) \cdot Q_{\text {th }}$ of $\mathrm{Li}_{2} \mathrm{MnO}_{3}$ and $\mathrm{LiNi}_{0.5} \mathrm{Mn}_{0.5} \mathrm{O}_{2}$ are $458 \mathrm{mAh} \cdot \mathrm{g}^{-1}$ and $273 \mathrm{mAh} \cdot \mathrm{g}^{-1}$, respectively. Taking into account the molar concentration of the compounds in the Li-rich electrode, the overall theoretical capacity is expected to be $378 \mathrm{mAh} \cdot \mathrm{g}^{-1}$.

The performance of electrode materials for Li-ion batteries reached today is the result of intensive research to reduce the size of particles to the nanoscale for three main reasons. One is the increase of the effective contact area of the powder with the electrolyte. A larger effective contact surface with the electrolyte means a greater probability to drain $\mathrm{Li}^{+}$ions from the electrode, which increases the power density of the cell. Secondly, nano-sized particles have larger surface areas and exhibit superior charge transfer kinetics. Thirdly, a smaller particle size also reduces the diffusion pathway of $\mathrm{Li}^{+}$ions to the interior of the particle, which leads to a greater capacity at higher charge/discharge rates and therefore to a larger power density [6,7]. Formally, the characteristic time (or $\mathrm{Li}^{+}$migration time), $\tau$, for the intercalation reaction is deduced from Fick's law:

$$
\tau=L^{2} / 4 \pi D^{*}
$$


where $L$ is the diffusion length and $D^{*}$ the chemical diffusion coefficient of $\mathrm{Li}^{+}$ions in the host lattice [7]. For a given chemical diffusion coefficient of $\mathrm{Li}^{+}$ions, $D^{*}$, the reduction of the size of the active particles from micro- to nano-scale implies a decrease in the characteristic time $\tau$ for the intercalation reaction by a factor of $10^{6}$, which corresponds to an enhancement of rate capability of the electrode. Nanoparticles, as well as more tailored nanostructures, are being explored and exploited to enhance the rate capability, even for materials with poor intrinsic electronic conductivity such as olivine frameworks. Therefore, in the present work, only materials under the form of nano-sized particles are investigated.

Among the materials capable of delivering high reversible capacity, the layered rhombohedral structures $\left(R \overline{3} m\right.$ space group) that are part of the solid-solution series $\mathrm{Li}\left(\mathrm{Ni}_{\mathrm{y}} \mathrm{Mn}_{\mathrm{z}} \mathrm{Co}_{1-\mathrm{y}-\mathrm{z}}\right) \mathrm{O}_{2}$ (called NMC hereafter) were first introduced by Liu et al. [8]. The symmetric $\mathrm{LiNi}_{1 / 3} \mathrm{Mn}_{1 / 3} \mathrm{Co}_{1 / 3} \mathrm{O}_{2}$ compound was proposed by Ohzuku's group in 2001 [9]. These materials are now widely studied as alternative 4-volt cathode materials to replace $\mathrm{LiCoO}_{2}$, exhibiting much higher voltage, great structural stability, and enhanced safety even at elevated temperature and higher reversible charge capacity [10-12]. However, the electrochemical performance of NMCs, i.e., capacity retention and long life cycling, strongly depend on the composition, the particle morphology, and the deviation from the ideal rock-salt structure [13]. The reversible specific capacity of NMC was measured to be $160 \mathrm{mAh} \cdot \mathrm{g}^{-1}$ in the cut-off potential range of $2.5-4.4 \mathrm{~V}$ and $200 \mathrm{mAh} \cdot \mathrm{g}^{-1}$ in that of $2.8-4.6 \mathrm{~V}$ [14]. In the $\mathrm{Li}_{1-x} \mathrm{Ni}_{1 / 3} \mathrm{Mn}_{1 / 3} \mathrm{Co}_{1 / 3} \mathrm{O}_{2}$ cathode, the charge/discharge process occurs with different oxidation states: the $\mathrm{Ni}^{2+} / \mathrm{Ni}^{4+}$ in the range $0 \leqslant x \leqslant 2 / 3$ and the couple $\mathrm{Co}^{3+} / \mathrm{Co}^{4+}$ is activated in the range $2 / 3 \leqslant x \leqslant 1$, while the electrochemically inactive $\mathrm{Mn}^{4+}$ ions play an important role by stabilizing the electrode structure [15]. The schematic representation of the energy diagram vs. density of states for $\mathrm{Li}_{\mathrm{x}} \mathrm{Ni}_{1 / 3} \mathrm{Mn}_{1 / 3} \mathrm{Co}_{1 / 3} \mathrm{O}_{2}$ is shown in Figure 2 for three states of charge (SOC). During the charge process, the Fermi level of the host material, $E_{\mathrm{F}}$, is lowered and for a high degree of delithiation $E_{\mathrm{F}}$ is pinned at the top of the $\mathrm{O}(2 \mathrm{p})$ band, which provides an intrinsic voltage limit for the cathode material [16].

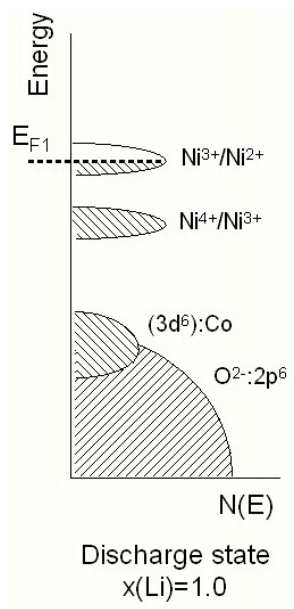

(a)

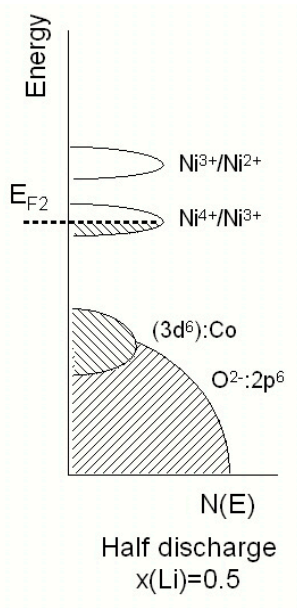

(b)

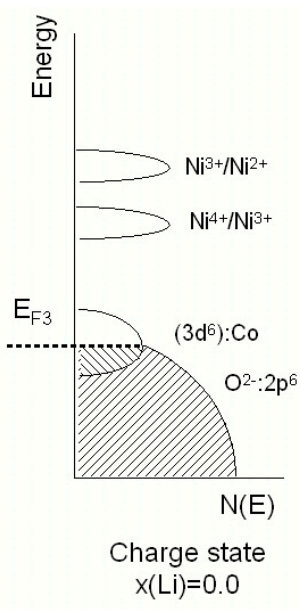

(c)

Figure 2. Schematic representation of the energy diagram vs. density of states for $\mathrm{Li}_{\mathrm{x}} \mathrm{Ni}_{1 / 3} \mathrm{Mn}_{1 / 3} \mathrm{Co}_{1 / 3} \mathrm{O}_{2}$ at different charge states. The Fermi level of the cathode material is represented for three state of charge. (a) Full discharge; (b) half discharge; (c) full charge.

In this work, nanostructured NMC cathode materials with different chemical configurations (see ternary phase diagram, Figure 3 were synthesized by wet-chemical methods. As the electrochemical performance of NMC materials is extremely dependent on the synthesis method and parameters, we report the influence of the recipe, the particle size and morphology, and the sample composition on electrochemical properties of NMC electrode materials. In addition to the cation mixing (structural defect), the crystallinity, phase purity, particle morphology, grain size, and surface area depend on the synthesis method, and they all play an important role in ionic and electronic 
transport [17]. A series of mixed transition-metal oxides $\mathrm{LiNi}_{\mathrm{w}} \mathrm{Mn}_{\mathrm{y}} \mathrm{Co}_{\mathrm{z}} \mathrm{O}_{2}$ samples is investigated for which the following parameters affecting their structural and electrochemical properties are considered: (i) effect of particle size; (ii) effect of the cation mixing; (iii) adjustment of the transition-metal/lithium ratio of the precursor; (iv) effect of chelating agent used in the synthesis; (v) effect of the synthesis recipe; (vi) slight deviation of the cobalt content in the symmetric NMC compound; and (vii) Li-rich integration in layered powders.

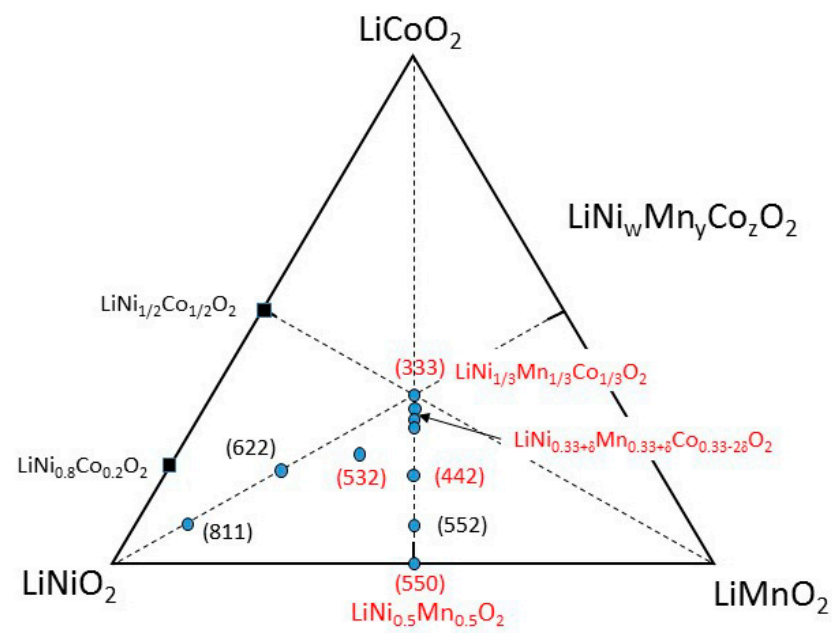

Figure 3. Ternary phase diagram of the mixed transition-metal oxides $\mathrm{LiNi}_{\mathrm{w}} \mathrm{Mn}_{\mathrm{y}} \mathrm{Co}_{\mathrm{z}} \mathrm{O}_{2}(w+y+z=1)$ formed by the $\mathrm{LiCoO}_{2}-\mathrm{LiNiO}_{2}-\mathrm{LiMnO}_{2}$ solid solutions. The compounds studied in this work are marked in red. The samples are noted $\left(w^{\prime} y^{\prime} z^{\prime}\right)$ where $w^{\prime}=10 w, y^{\prime}=10 y$ and $z^{\prime}=10 z$.

\section{Experimental}

\subsection{Synthesis Procedures}

Layered compounds were synthesized by either solid-state reaction or wet chemistry ("chimie douce"). These solution methods consist of acidification of aqueous solution of the starting compounds was used to prepare the layered cathode materials. The acidification is generally realized by using carboxylic acids. Three classes can be considered according the synthetic process: sol-gel, co-precipitation, and combustion [18-20]. The synthesis routes for the different samples are as follows: (1) $\mathrm{LiNi}_{0.55} \mathrm{Co}_{0.45} \mathrm{O}_{2}$ and $\mathrm{NMC}$ powders were prepared by solid-state reaction at $850{ }^{\circ} \mathrm{C}$ in air as shown elsewhere [21]; (2) $\mathrm{LiNi}_{0.55} \mathrm{Co}_{0.45} \mathrm{O}_{2}$ nano-powders were synthesized by hydrothermal method using acetate raw materials [22]; (3) a series of mixed transition-metal oxides $\mathrm{LiNi}_{\mathrm{w}} \mathrm{Mn}_{\mathrm{y}} \mathrm{Co}_{\mathrm{z}} \mathrm{O}_{2}$ $(w+y+z=1)$ were synthesized by the co-precipitation method. This consists of a hydroxide route using transition-metal hydroxide and lithium carbonate as starting materials, as reported elsewhere [23]. (4) $\mathrm{Li}_{1+x}\left(\mathrm{Ni}_{1 / 3} \mathrm{Mn}_{1 / 3} \mathrm{Co}_{1 / 3}\right)_{1-x} \mathrm{O}_{2}$ powders were prepared by a hydroxide route using an aqueous solution in which the $\mathrm{pH}$ was controlled with care using simultaneously $\mathrm{NaOH}$ and $\mathrm{NH}_{4} \mathrm{OH}$ fed into the reactor; (5) a series of symmetric $\mathrm{LiNi}_{1 / 3} \mathrm{Mn}_{1 / 3} \mathrm{Co}_{1 / 3} \mathrm{O}_{2}$ powders was prepared by the precipitation technique using metal acetates as raw materials and succinic acid as a chelating agent. Different acid to metal-ion molar ratios $R$ were used to study the effect of this parameter on the structural properties of the final product; (6) A series of NMC powders were synthesized by co-precipitation assisted by single dicarboxyl (oxalic) and complexed dicarboxyl (tartaric) acid; (7) a series of $\mathrm{LiNi}_{0.33+\delta} \mathrm{Mn}_{0.33+\delta} \mathrm{Co}_{0.33-2 \delta} \mathrm{O}_{2}$ with different values of $\delta$ was obtained by the sol-gel route assisted by citric acid (tricarboxyl) in keeping the $\mathrm{pH}$ of the solution in the range $5-6$; (8) Li-rich $\mathrm{Li}\left(\mathrm{Li}_{1 / 3-2 \mathrm{x} / 3} \mathrm{Ni}_{\mathrm{x}} \mathrm{Mn}_{2 / 3-\mathrm{x} / 3}\right) \mathrm{O}_{2}(0 \leqslant x \leqslant 0.5)$ powders were synthesized by a citrate-gel method using acetate salts. Citric acid was dropped wisely to the solution under continuous stirring for $6 \mathrm{~h}$ with molar ratio $1: 1$ of $(\mathrm{Li}+\mathrm{Ni}+\mathrm{Mn}): \mathrm{C}_{6} \mathrm{H}_{8} \mathrm{O}_{7}$ to adjust the $\mathrm{pH}$ value to $7-8$ with ammonium hydroxide. 
All final products were obtained by sintering the powders at an optimum sintering temperature of $T=900^{\circ} \mathrm{C}$ in air for a few hours.

\subsection{Characterizations}

The structure of the samples was investigated using X-ray diffractometer (XRD) (PANalytical $X^{\prime}$ Pert, Lelyweg, The Netherlands) using nickel-filtered $\mathrm{Cu}-\mathrm{K} \alpha$ radiation. The diffractograms were taken at room temperature in the $2 \theta$ range $10^{\circ}-80^{\circ}$. Thermogravimetry (TG) analysis was performed using a Pyris1 instrument analyser (Perkin-Elmer, Sheffield, UK) to monitor the weight loss/gain and heat treatment processes under a flow of dry air with a $10{ }^{\circ} \mathrm{C} / \mathrm{min}$ heating rate. The specific surface area was analysed by the Brunauer-Emmett-Teller (BET) method using Micromeritics ASAP 2010 in which the $\mathrm{N}_{2}$ gas adsorption was employed. The morphology and composition of the samples were investigated by scanning electron microscopy ZEISS model ULTRA 55 (Jena, Germany), equipped with an energy-dispersive X-ray spectrometer (EDX). HRTEM images were obtained using an electronic microscope JEOL model JEM-2010 (Pleasanton, CA, USA). The magnetic measurements (susceptibility and magnetization) were performed with two fully automated SQUID magnetometers (Quantum Design MPMS-5S, San Diego, CA, USA) in the temperature range 4-300 K, as described elsewhere [24].

\subsection{Electrochemical Tests}

Electrochemical tests were conducted on CR2025-type coin cells. The positive electrodes were constituted of $80 \mathrm{wt} \%$ active material, $10 \mathrm{wt} \%$ carbon black as conductive material and $10 \mathrm{wt} \%$ polyvinylidene fluoride (PVDF) in N-methyl pyrrolidinone (NMP) solvent, mixed and ground to form a homogeneous slurry. The slurry was then spread onto an aluminium foil current collector and dried at $80{ }^{\circ} \mathrm{C}$ for $2 \mathrm{~h}$ to remove the solvent before being pressed. The cathode loading was in the range $5-7 \mathrm{mg} \cdot \mathrm{cm}^{-2}$. The cells were assembled in a glove box (moisture and oxygen content $\leqslant 5 \mathrm{ppm}$ ) under argon atmosphere using lithium sheet as the counter electrode, Celgard 2300 film (MTI, Richmond, CA, USA) as the separator, and $1 \mathrm{~mol} \cdot \mathrm{L}^{-1} \mathrm{LiPF}_{6}$ in ethylene carbonate (EC)/diethyl carbonate (DEC) (1:1) solution as electrolyte (LP30, Merck, Darmstadt, Germany). The galvanostatic charge-discharge curves were performed using a potentiostat/galvanostat (VMP3 Bio-Logic, Claix, France) in the potential range $2.0-4.8 \mathrm{~V}$.

\section{Results and Discussion}

\subsection{The Effect of Particle Size}

The main drawback of layered of TMOs is their poor discharge rate capability due to low intrinsic electronic and ionic conductivity. Thus, at high current densities, i.e., $J>1 \mathrm{C}$ rate (the rate is denoted $\mathrm{C} / \mathrm{n}$, where $\mathrm{C}$ is the theoretical cathode capacity and a full discharge occurs in $\mathrm{n}$ hours), the poor electrochemical performance is attributed to the low electron transport of the material and the slow Li-ion kinetics within the grains. The currently adopted approach to get high rate capability is to reduce the diffusion path length of charge species by minimizing the particle size of the active phase [25]. For instance, Okubo et al. [26] have observed an excellent high-rate capability, i.e., $65 \%$ of the $1 \mathrm{C}$ rate capability at $100 \mathrm{C}$, in nanocrystalline $\mathrm{LiCoO}_{2}$ with an appropriate particle size of $17 \mathrm{~nm}$. In this context, based on the Li-ion diffusion coefficient $D^{*} \approx 2.5 \times 10^{-12} \mathrm{~cm}^{2} \cdot \mathrm{s}^{-1}$, the discharge process of $100 \mathrm{~s}$ requires particle size $L=100 \mathrm{~nm}$ against $1 \mathrm{~h}$ for $L=2 \mu \mathrm{m}$. Thus, 100-nm sized particles can be fully charged/discharged even at $10 \mathrm{C}$ rate $\left(1.4 \mathrm{~A} \cdot \mathrm{g}^{-1}\right)$. It was also demonstrated that control of the particle size is obtained via synthetic methods such as sol-gel [27], hydrothermal process [28], etc. As an example of the particle size effect, $\mathrm{LiNi}_{0.55} \mathrm{Co}_{0.45} \mathrm{O}_{2}$ (NCO) compounds were investigated. Figure 4 shows the HRTEM images of NCO particles and the discharge capacity curves of the corresponding $\mathrm{Li} / / \mathrm{LiNi}_{0.55} \mathrm{Co}_{0.45} \mathrm{O}_{2}$ coin-type cells as a function of $\mathrm{C}$-rate. The cathode material (a) prepared by hydrothermal method has nanometric particles, 100-150 nm average size, while the micron-sized material, 1.5-2.0 $\mu \mathrm{m}$ particle size, was prepared by a two-step co-precipitation technique. An obvious 
difference in the electrochemical performance is observed. The Li cell with nano-sized particles allows a specific capacity $150 \mathrm{mAh} \cdot \mathrm{g}^{-1}$ for $1 \mathrm{C}$ discharge rate, which is twice the capacity of the cell with micro-sized particles. The excellent rate capability makes nano- $\mathrm{LiNi} \mathrm{Ni}_{05} \mathrm{Co}_{0.45} \mathrm{O}_{2}$ suitable for high-power LIBs. Note that battery cycle life is favored by the architecture of the cathode material at the sub-micron scale, which allows the accommodation of volume changes caused by $\mathrm{Li}^{+}$ions insertion/extraction into/from the single particle due to faster stress relaxation.
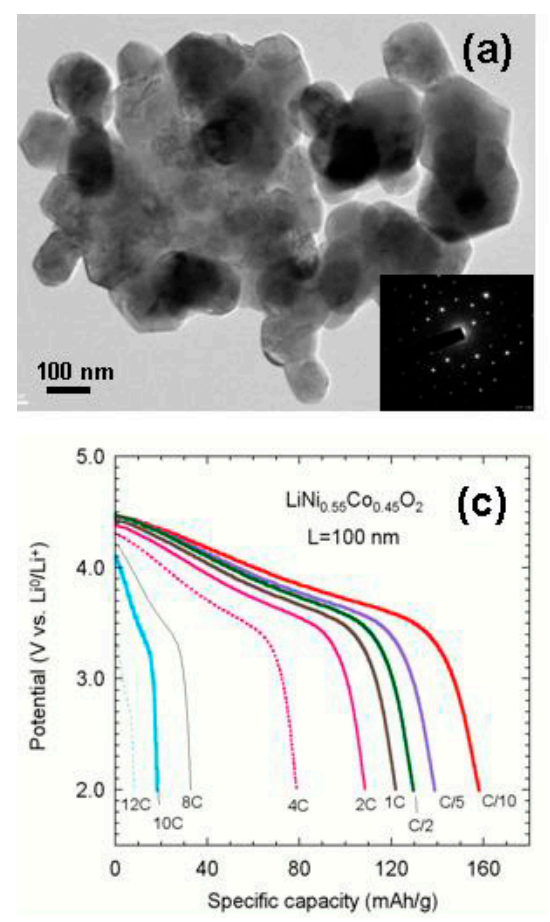
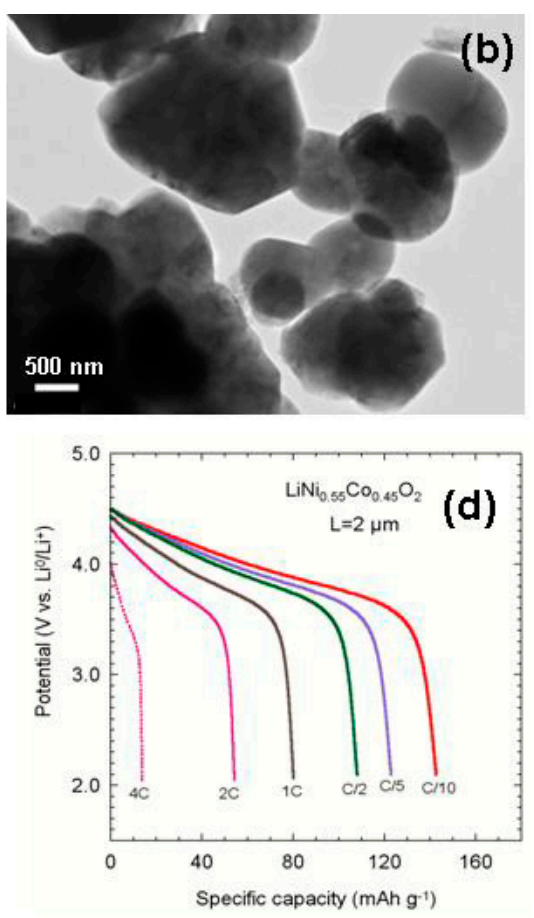

Figure 4. HRTEM images of $\mathrm{LiNi}_{0.55} \mathrm{Co}_{0.45} \mathrm{O}_{2}$ layered powders with different particle sizes: ca. $\quad 100-150 \mathrm{~nm}$ (a) and 1.5-2.0 $\mathrm{mm}$ (b) and discharge profiles as a function of C-rate for $\mathrm{Li} / / \mathrm{LiNi}_{0.55} \mathrm{Co}_{0.45} \mathrm{O}_{2}$ coin-type cells with two cathode materials of $100 \mathrm{~nm}$ and $2 \mu \mathrm{m}$ particle size. The good crystallinity of powders is shown by the electron diffraction diagram (inset); (c) discharge curves for 100-150 nm; (d) discharge curves for 1.5-2.0 $\mu \mathrm{m}$.

\subsection{The Effect of Cationic Mixing}

In this section, we report the properties of mixed transition-metal oxides $\mathrm{LiNi}_{\mathrm{w}} \mathrm{Mn}_{\mathrm{y}} \mathrm{Co}_{\mathrm{z}} \mathrm{O}_{2}$ as 4-volt cathode materials for Li-ion batteries, for which the electrochemical features are correlated with structure and morphology of active particles. Special attention is given to the influence of the cation mixing between $\mathrm{Li}^{+}$and $\mathrm{Ni}^{2+}$ ions on the crystallographic $(3 b)$ sites of the layered lattice due to the fact that the ionic radius of $\mathrm{Ni}^{2+}(0.69 \AA)$ close to that of $\mathrm{Li}^{+}(0.76 \AA)$ in an octahedral environment. A partial occupation of $\mathrm{Li}(3 b)$ sites generates a disorder, so-called "cation mixing", in the structure that damages the electrochemical performance [29-31]. Figure 5 presents the SEM images of three NMC samples prepared by solid-state reaction at $850{ }^{\circ} \mathrm{C}$ in air with composition $333,442,532$. The surface morphology of NMC particles displays powders formed by aggregates of primary particles, which appear as small column-shaped particles. Typical dimensions of the small columned particle are $0.5 \mu \mathrm{m} \times 2 \mu \mathrm{m}$ for the 333 compound. The SEM images of samples 442 and 532 display spherical secondary powders formed by aggregates of primary particles, which appear as small cubic-shaped particles. The formation of spherical secondary particle is beneficial for achieving a high tap density and energy density. In addition, it should be noted that, in cathode materials, the $\mathrm{Li}^{+}$ ion diffusion not only depends on the size of primary particles but on the morphology and porosity of the secondary particles. 

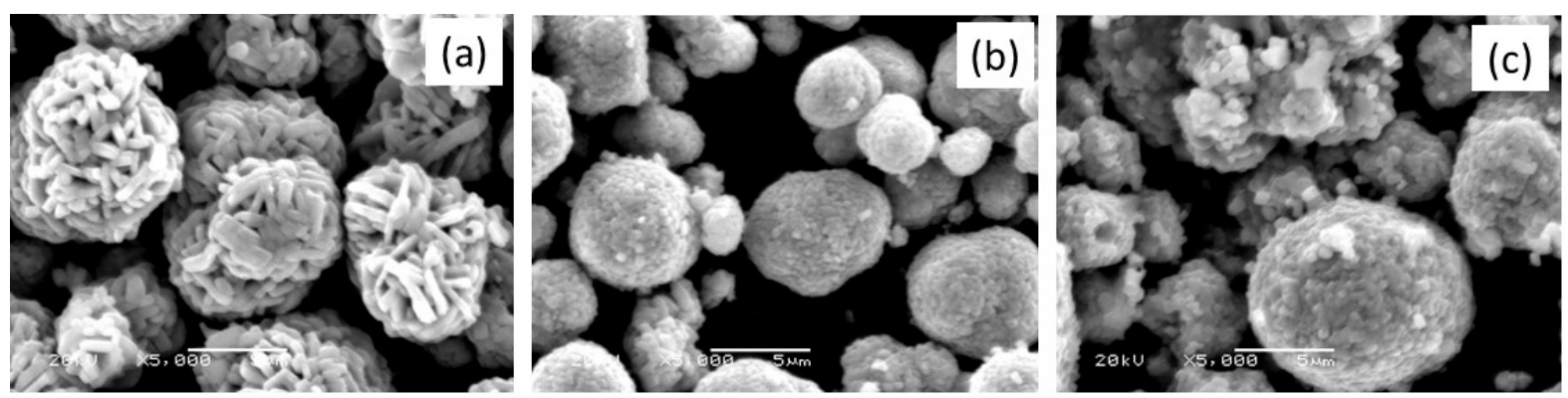

Figure 5. SEM images of NMC samples: (a) 333; (b) 442; and (c) 532 compounds prepared by solid-state reaction at $850{ }^{\circ} \mathrm{C}$ in air.

Structural investigations (X-ray diffraction and Raman spectroscopy) show that the samples calcined at $850{ }^{\circ} \mathrm{C}$ exhibit the typical rhombohedral $\alpha-\mathrm{NaFeO}_{2}$ structure ( $R \overline{3} m$ S.G) without any other impurity phases. XRD data were refined by the Rietveld method, using the structural model $\left(\mathrm{Li}_{1-\delta} \mathrm{Ni}_{\delta}\right)_{3 b}\left(\mathrm{Li}_{\delta} \mathrm{Ni}_{\mathrm{x}-\delta} \mathrm{Mn}_{\mathrm{y}} \mathrm{Co}_{1-\mathrm{x}-\mathrm{y}}\right)_{3 a} \mathrm{O}_{2}$ (see details in [32]). The results are shown in Figure 6 and the data refinements are listed in Table 1 . The cation mixing corresponds to an antisite defect noted $\mathrm{Ni}_{\mathrm{Li}}$, which means that $\mathrm{Ni}^{2+}$ occupies a $\mathrm{Li}^{+}$site that is compensated for by the opposite, i.e., $\mathrm{Li}^{\prime}{ }_{\mathrm{Ni}}$, corresponding to a $\mathrm{Li}^{+}$ion on a $\mathrm{Ni}^{2+}$ site preferentially close to it, to result in a neutral $\mathrm{Ni}_{\mathrm{Li}}+\mathrm{Li}{ }^{\prime} \mathrm{Ni}$ pair, with one $\mathrm{Ni}^{2+}$ ion on a $3 b$ site plus one $\mathrm{Li}^{+}$on a $3 a$ site. The fraction of $\mathrm{Li}^{+}$on $3 a$ sites, which is the concentration of such antisite defects, is called $\eta$. Indeed, as expected, the concentration of $\mathrm{Ni}(3 b)$ defects and then the $\mathrm{Li}^{+} / \mathrm{Ni}^{2+}$ cation mixing is less $(\eta=1.56 \%)$ for the 333 compound. The $c / a$ value is related to the degree of trigonal distortion, a higher cation ordering being achieved when $c / a>4.899$. The evolution of this ratio with $z$ in Table 1 indicates that the substitution of $\mathrm{Co}$ for $\mathrm{Mn}$ in $\mathrm{LiNi}_{\mathrm{w}} \mathrm{Mn}_{\mathrm{y}} \mathrm{Co}_{\mathrm{z}} \mathrm{O}_{2}$ promotes the formation of the layered lattice [30]. The trigonal distortion $c / a$ is largest for the 333 compound and lowest for the 532 one, which indicates that a smaller concentration of $\mathrm{Ni}$ results in a better layered ordering and smaller concentration of $\mathrm{Li}^{+} / \mathrm{Ni}^{2+}$ cation mixing.

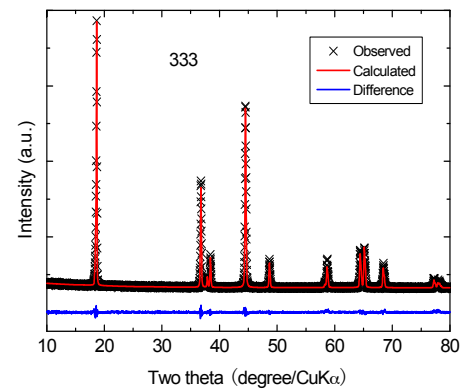

(a)

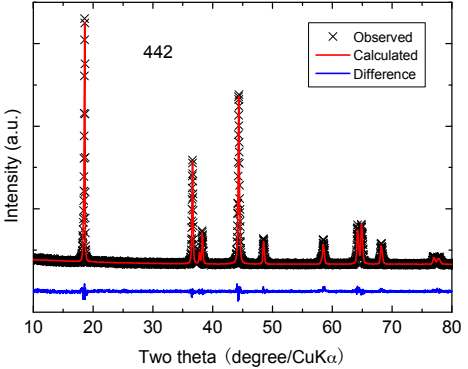

(b)

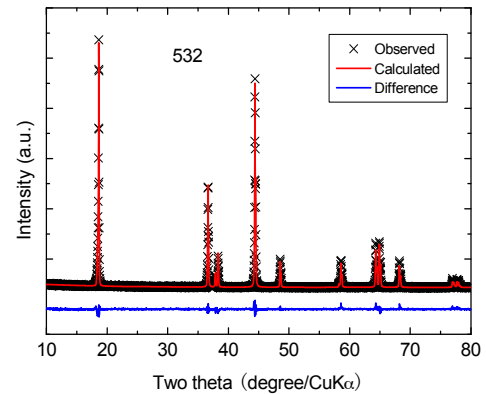

(c)

Figure 6. Rietveld refinement patterns of NMC samples: (a) 333; (b) 442; (c) 532 synthesized by solid-state reaction. The cross marks show observed XRD intensities and the solid line (red) represents calculated intensities. The curve at the bottom (blue) is the difference between the calculated and observed intensities on the same scale.

The cation mixing would attract oxygen ions from adjacent oxygen layers, thereby locally shortening the oxygen-oxygen distance between neighbouring $M_{2}(M=\mathrm{TM}$ ions on $3 b$ layer $)$ slabs. Moreover, the Li-ions migrating between two neighbouring octahedral sites in the same lithium layer are also required to pass through an empty tetrahedral site. The decrease in the oxygen-oxygen distance would increase the activation energy for the Li-ion motion [32]. Furthermore, the $\mathrm{Ni}^{2+}(3 b)$ ions would exert a strong electrostatic repulsion on the Li ions and drastically hamper their reinsertion. The sample with a higher concentration of cation mixing would induce very high Li diffusion barrier 
in less-ordered materials, resulting in its relatively worse electrochemical performance. For 442 and 333 compounds, the charge compensation is achieved by stabilization of $\mathrm{Ni}^{2+}, \mathrm{Mn}^{4+}$, and $\mathrm{Co}^{3+}$. Due to the excess of nickel-ion in the 532 compound, the charge neutrality requires the oxidation of $\mathrm{Ni}^{2+}\left(0.2 \mathrm{~mol}\right.$ per chemical formula) to $\mathrm{Ni}^{3+}$. The amount of cation mixing estimated from magnetic measurements is consistent with the $\mathrm{XRD}$ results.

Table 1. Lattice parameters $a, c, c / a$ of NMC materials, synthesized by solid-state reaction. $V$ is the volume of the unit cell. $L$ is the mean lattice coherence length. The last column is the ratio of the intensities of the XRD lines labelled by their Miller indexes and $R=\left(I_{006}+I_{102}\right) / I_{101}$. The parameter $\eta$ reveals the site-exchange rate of $\mathrm{Ni}^{2+}(3 b)$ cation mixing.

\begin{tabular}{ccccccccc}
\hline Sample & $\boldsymbol{a}(\mathbf{\AA})$ & $\boldsymbol{c}(\AA)$ & $\boldsymbol{c} / \boldsymbol{a}$ & $\boldsymbol{V}\left(\AA^{\mathbf{3}}\right)$ & $\boldsymbol{L}(\mathbf{n m})$ & $\boldsymbol{I}_{\mathbf{0 0 3}} / \mathbf{I}_{\mathbf{1 0 4}}$ & $\boldsymbol{R}$ & $\eta(\mathbf{\%})$ \\
\hline 550 & $2.8833(2)$ & $14.3251(2)$ & 4.948 & $119.08(9)$ & 59.9 & 1.197 & 0.420 & 6.70 \\
$4_{1 / 2} 4_{1 / 2} 1$ & $2.8766(8)$ & $14.3005(5)$ & 4.971 & $118.33(2)$ & 65.5 & 1.209 & 0.418 & 5.31 \\
532 & $2.8732(2)$ & $14.2684(4)$ & 4.966 & $102.01(2)$ & 61.6 & 1.252 & 0.415 & 3.34 \\
\hline 442 & $2.8685(1)$ & $14.2655(3)$ & 4.973 & $101.65(1)$ & 64.6 & 1.425 & 0.401 & 2.97 \\
333 & $2.8604(2)$ & $14.2376(2)$ & 4.977 & $100.88(2)$ & 72.3 & 1.456 & 0.387 & 1.56 \\
334 & $2.8622(3)$ & $14.2455(7)$ & 4.977 & $116.70(2)$ & 63.8 & 1.450 & 0.395 & 1.77 \\
$1 / 41 / 4^{1 / 2}$ & $2.8628(5)$ & $14.2259(6)$ & 4.981 & $116.86(6)$ & 62.0 & 1.452 & 0.390 & 0.70 \\
\hline
\end{tabular}

Figure 7 displays the typical discharge profiles of different Li//NMC cells with cathodes synthesized by the solid-state reaction method. The electrochemical tests were carried out at discharge rate $\mathrm{C} / 5$ in the voltage window $2.8-4.6 \mathrm{~V}$ vs. $\mathrm{Li}^{0} / \mathrm{Li}^{+}$. The dependence of the specific capacity on the composition is clearly seen. We observe smooth discharge curves with an average voltage near $3.80 \mathrm{~V}$. The best result is obtained for the symmetric 333 compound, which exhibits a small irreversible capacity loss (5.5 mAh. $\left.\mathrm{g}^{-1}\right)$ at the first cycle, against $22 \mathrm{mAh} \cdot \mathrm{g}^{-1}$ for the $\mathrm{LiNi}_{0.5} \mathrm{Mn}_{0.5} \mathrm{O}_{2}$ electrode. The discharge curves show the typical one-step behaviour characteristic of these layered compounds. These results illustrate the drastic change due to the introduction of a fraction of $\mathrm{Co}$ in the $\mathrm{LiNi}_{\mathrm{y}} \mathrm{Mn}_{\mathrm{y}} \mathrm{Co}_{1-2 \mathrm{y}} \mathrm{O}_{2}$ lattice. The 333 cell discharged at C/5 delivers a reversible capacity of ca. $180 \mathrm{mAh} \cdot \mathrm{g}^{-1}$ with a capacity retention of $88 \%$ after 50 cycles, while $72 \%$ is obtained for the 550 compound. The negative effects of cation mixing $\eta$ and decrease of the oxygen-oxygen distance on the electrochemical properties, which we have discussed above, is well evidenced by comparing the results in Figure 7 and in Table 1. For instance, the capacity delivered by the 442 sample is smaller than that of the 333 sample, because the concentration of antisite defects $\eta$ is larger.

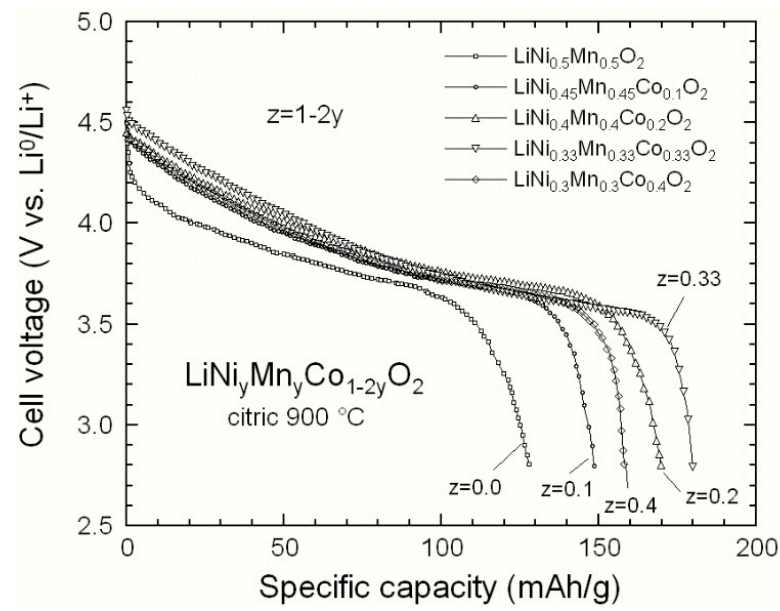

Figure 7. Typical discharge profiles of different Li//NMC cells with cathodes synthesized by the solid-state reaction route at $850{ }^{\circ} \mathrm{C}$. The electrochemical test were carried out at discharge rate $\mathrm{C} / 5 \mathrm{in}$ the voltage window $2.8-4.6 \mathrm{~V}$ vs. $\mathrm{Li}^{0} / \mathrm{Li}^{+}$. 
As a typical example of an electrochemical test, Figure 8 presents the discharge profiles as a function of C-rate for the $\mathrm{Li} / / \mathrm{LiNi}_{0.4} \mathrm{Mn}_{0.4} \mathrm{Co}_{0.2} \mathrm{O}_{2}$ coin cell cycled in the potential range 2.5-4.4 V vs. $\mathrm{Li}^{0} / \mathrm{Li}^{+}$. This is a typical illustration of the rate capability of the 442 compound grown by wet chemistry, which is considered as having the highest capacity and maintaining its capacity on cycling [33-36]. The cell discharged at C/25 delivers a reversible capacity of $160 \mathrm{mAh} \cdot \mathrm{g}^{-1}$, with a coulombic efficiency of $88 \%$ at the first cycle. These data are similar to those reported by Tran et al. for $\mathrm{LiNi}_{0.425} \mathrm{Mn}_{0.425} \mathrm{Co}_{0.15} \mathrm{O}_{2}$ [34]. Upon further cycling, the capacity retention remains quite stable despite a rather large amount $(2.71 \%)$ of $\mathrm{Ni}^{2+}$ antisites in the lithium interslab space of the 442 material. The continuous fall of the capacity against the increasing current density is attributed to the low electronic conductivity of $1.4 \times 10^{-4} \mathrm{~S} \cdot \mathrm{cm}^{-1}$ for $\mathrm{LiNi}_{0.4} \mathrm{Mn}_{0.4} \mathrm{Co}_{0.2} \mathrm{O}_{2}$ [35]. The good electrochemical performance has also been pointed out by Tsai et al. [37] from X-ray absorption spectroscopy. The inhibition of structure distortion during the delithiation and lithiation cycle originates from a balance of the repulsive force and the size effect in the layered compound. Upon further cycling, the capacity retention remains quite stable despite a rather large amount (ca. $3 \%$ ) of $\mathrm{Ni}^{2+}$ in the interslab site of the 442 material. Cycling with the upper potential of $4.5 \mathrm{~V}$, the cell delivered a capacity of about $170 \mathrm{mAh} \cdot \mathrm{g}^{-1}$ at a specific current of $40 \mathrm{~mA} \cdot \mathrm{g}^{-1}(\mathrm{C} / 15)$. The tests of electrochemical performance and limit of discharge rate in NMC were obtained from the Peukert plot (insert in Figure 8), which revealed that the 442 compound delivers almost half of the initial capacity at $2 \mathrm{C}$ rate.

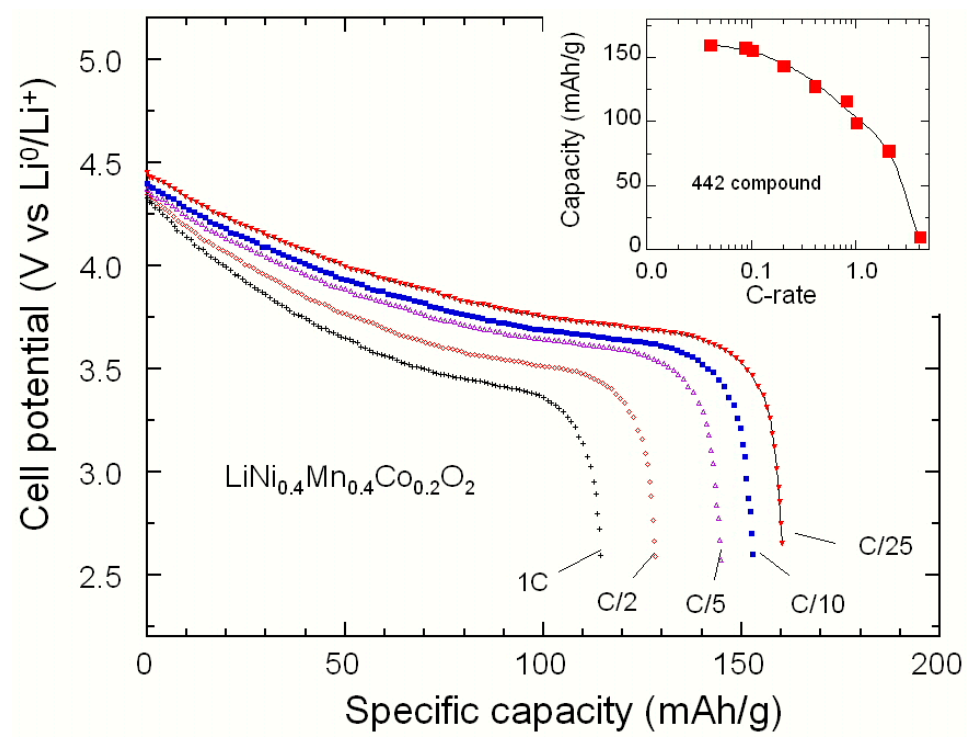

Figure 8. Discharge profiles vs. specific capacity of the $\mathrm{Li} / / \mathrm{LiNi}_{0.4} \mathrm{Mn}_{0.4} \mathrm{Co}_{0.2} \mathrm{O}_{2}$ cells between 2.5 and $4.4 \mathrm{~V}$ at various $\mathrm{C}$-rates. The inset shows the rate capability of the 442 compound.

The open-circuit curve or the discharge profile at low rate (solid line at $\mathrm{C} / 25$ in Figure 8) for the $\mathrm{Li} / / \mathrm{LiNi}_{0.4} \mathrm{Mn}_{0.4} \mathrm{Co}_{0.2} \mathrm{O}_{2}$ cell can be modelled by the equation:

$$
E(x)=\sum_{n=1}^{i}\left(E_{i}^{o}+\frac{R T}{F} \ln \frac{x_{i}}{x_{\max }-x_{i}}+\frac{R T}{F} K_{i} x_{i}\right)
$$

The fitting parameter $K_{i}$ reveals the interactions between the inserted $\mathrm{Li}^{+}$and the available sites of the host. The parameter $K$ is a lateral interaction parameter that is introduced to represent the effects of the interactions in a two-dimensional process: $K>0$ for a repulsive interaction, $K=0$ for an absence of any interaction, $0>K>-4$ for attractive interaction between the intercalation sites, $K=-4$ is a critical state, while for $K<-4$ the interactions are so intensive that they lead to the existence of two-phase reactions. 
For NMC insertion compounds, we consider two redox processes labelled by the index $I=1,2$. The first process is associated to the valence change of the nickel ions: $\mathrm{Ni}^{2+} \rightarrow \mathrm{Ni}^{3+} \rightarrow \mathrm{Ni}^{4+}$. The first step of delithiation extends from the lithium concentration of lithium on $3 b$ sites:

$$
x_{\max , 1}=1
$$

until the $\mathrm{Ni}$ ions have been converted into $\mathrm{Ni}^{3+}$, in which case $x=1-y$. In Equation (5), we have neglected the amount of lithium on the $3 a$ sites, which is justified by the fact that the concentration of antisites is few per cent only. Then, $\mathrm{Ni}^{3+}$ ions can be converted to $\mathrm{Ni}^{4+}$ until $x=1-2 y$, where all the nickel ions have been converted in the $\mathrm{Ni}^{4+}$ valence state. At this concentration a second redox process $\mathrm{Co}^{3+} \rightarrow \mathrm{Co}^{4+}$ begins, which extends from

$$
x_{\max , 2}=1-2 y
$$

down to $x=0$, where all the cobalt ions have been converted to the tetravalent state. Note we have implicitly assumed that the different processes do not overlap. This has been justified in [38], where we have shown from the analysis of magnetic measurements that the concentration $y^{\prime}$ of $\mathrm{Ni}^{3+}$ at the concentration $x_{\max , 2}$ does not exceed $2 \%$, which is the uncertainty in the determination of $y^{\prime}$.

The best fit (Figure 8) for the 442 cathode material is obtained with two redox processes with standard potential $E_{0,1}=3.731 \mathrm{~V}$ and $E_{0,2}=3.955 \mathrm{~V}$ and interaction factor $K_{1}=-3.75$ and $K_{2}=-2.98$. Since the interaction is smaller than the critical case $K_{\mathrm{c}}=-4$ we are not in the case of a two-phase regime, and indeed there is no plateau in the curves in Figures 7 and 8. Table 2 lists the electrochemical parameters of NMC materials studied in Figure 8.

Table 2. Electrochemical parameters of NMC materials calculated from Equation (4) at low rate of $\mathrm{C} / 20$. $(1-2 \mathrm{y})$ is the cobalt concentration in the $\mathrm{LiNi}_{\mathrm{y}} \mathrm{Mn}_{\mathrm{y}} \mathrm{Co}_{1-2 \mathrm{y}} \mathrm{O}_{2}$ structure.

\begin{tabular}{cccccc}
\hline Cathode & $\mathbf{( 1 - 2 y )}$ & $\boldsymbol{E}_{\mathbf{0 , \mathbf { 1 }}} \mathbf{( V )}$ & $-\boldsymbol{K}_{\mathbf{1}}$ & $\boldsymbol{E}_{\mathbf{0 , 2}}(\mathbf{V})$ & $-\mathbf{K}_{\mathbf{2}}$ \\
\hline 550 & 0.00 & 3.737 & 3.82 & 3.869 & 3.12 \\
$4_{1 / 2} 4_{1 / 2} 1$ & 0.10 & 3.734 & 3.75 & 3.903 & 2.98 \\
442 & 0.20 & 3.731 & 3.75 & 3.955 & 2.98 \\
333 & 0.33 & 3.722 & 3.71 & 3.932 & 3.00 \\
334 & 0.40 & 3.717 & 3.78 & 3.921 & 3.01 \\
\hline
\end{tabular}

However, we know from Table 1 that the cation mixing decreases linearly with the concentration of cobalt $1-2 y$ from $\eta=7 \%$ for $(1-2 y)=0$ to $0.7 \%$ for $(1-2 y)=0.5$. While the increase of cation mixing has important effects on the electrochemical properties that we have evidenced in Figure 8 for instance, we find here that it has very little effect on the parameters in Table 2 . The reason is that the increase of the cobalt concentration increases the electrical conductivity and the correlated decrease of the cation mixing increases the ionic conductivity, hence the beneficial impact on the electrochemical properties. On the other hand, the parameters in Table 2 are parameters of the redox reactions that are only sensitive to the average crystallographic environment of the nickel and cobalt ions, which is not significantly disturbed by few \% cation mixing in the lattice.

\subsection{Adjustment of the Li/M Ratio}

Another way to optimize an electrode active material consists in the adjustment of one parameter of the synthesis, namely the lithium/transition metal molar ratio in $\mathrm{Li}_{1+\mathrm{x}}(\mathrm{NMC})_{1-\mathrm{x}} \mathrm{O}_{2}(\mathrm{NMC}=333)$ to minimize the cation mixing [30]. Two independent experimental procedures are used to estimate the cation mixing $(\eta)$ : structural refinements of XRD patterns made by the Rietveld method, which accurately determine the $M$ occupancy between slabs of the layered lattice; (ii) magnetic measurements, which are powerful to check the quality of material and structural properties at the nano-scale [39] of samples synthesized by the co-precipitation method from a hydroxide precursor assisted by 
ammonium and sodium hydroxides [40]. The elemental titration carried out by ICP of the two samples prepared by a hydroxide route with nominal $\Psi=\mathrm{Li} / \mathrm{M}$ ratio $(\Psi=1.05$ and 1.10$)$ shows the technological composition of Li-rich $\mathrm{Li}_{1+x}\left(\mathrm{Ni}_{1 / 3} \mathrm{Mn}_{1 / 3} \mathrm{Co}_{1 / 3}\right)_{1-\mathrm{x}} \mathrm{O}_{2}$ with $\mathrm{x}=0.02$ and 0.04 , respectively. Note that the $\mathrm{Li} / \mathrm{M}$ ratios of the samples are $(1+\mathrm{x}) /(1-\mathrm{x})=1.04$ and 1.08 , respectively, close to the nominal ratio $\Psi$. This gives evidence that the amount of Li that has evaporated during the synthesis is very small ( $1 \%-2 \%$ only), and comparable to the case when the samples are prepared by the Pechini method [40]. The morphology of particles is shown in Figure 9. The SEM micrograph displays powders formed by agglomerates of primary particles, which appear as small, column-shaped particles of typical dimension $0.5 \mu \mathrm{m} \times 2 \mu \mathrm{m}$. The HRTEM image shows the good crystallinity of the individual nanoparticles. Apparent lattice fringes can be observed and the width of $0.472 \mathrm{~nm}$ between lattice fringes is consistent with the interspacing of the (003) planes of the layered structure $R \overline{3} m$ space group.
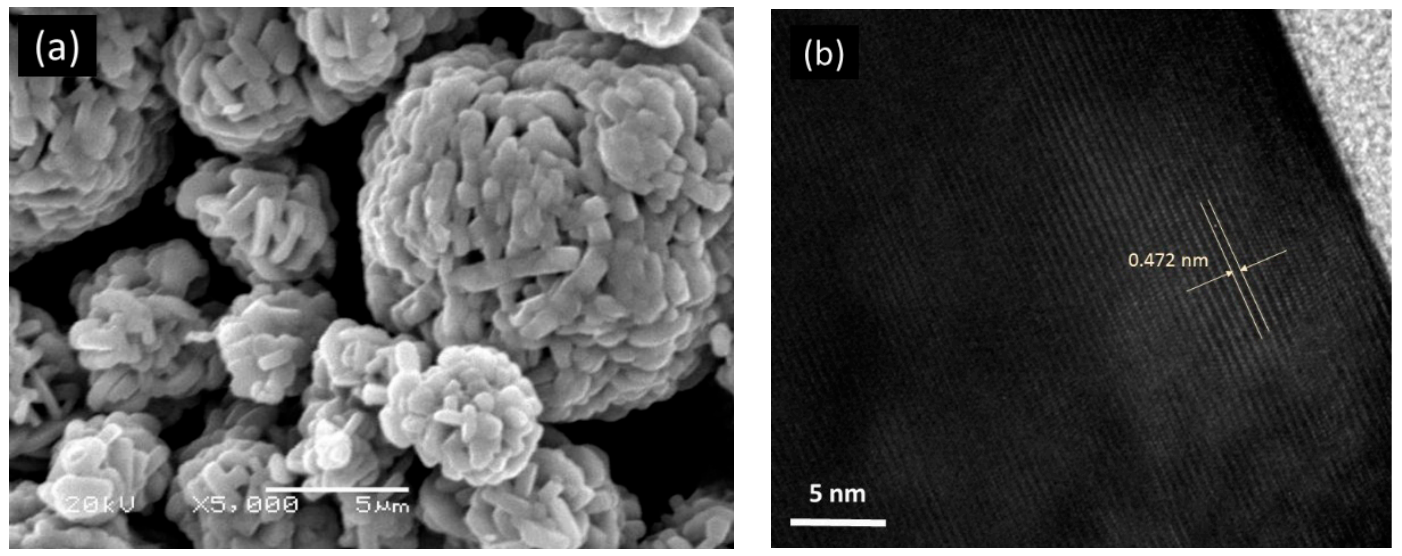

Figure 9. SEM (a) and HRTEM (b) images of $\mathrm{Li}_{1.04} \mathrm{Ni}_{0.32} \mathrm{Mn}_{0.32} \mathrm{Co}_{0.32} \mathrm{O}_{2}$ powders synthesized the co-precipitation method from hydroxide precursor assisted by ammonium and sodium hydroxides.

If $u$ is the concentration of $\mathrm{Ni}^{*} \mathrm{Li}+\mathrm{Li}^{\prime} \mathrm{Ni}$ pair defects, the detailed chemical formula is then $\left(\mathrm{Li}_{1-\mathrm{u}} \mathrm{Ni}_{\mathrm{u}}\right)_{3 \mathrm{~b}}\left(\mathrm{Li}_{\mathrm{x}+\mathrm{u}} \mathrm{Ni}_{(1-\mathrm{x}) / 3-\mathrm{u}} \mathrm{Mn}_{(1-\mathrm{x}) / 3} \mathrm{Co}_{(1-\mathrm{x}) / 3}\right)_{3 \mathrm{a}} \mathrm{O}_{2}$ for Rietveld analysis: both $x$ and $u$ were refined, from which the fraction $\eta$ of $\mathrm{Li}$ on $3 a$ sites has been deduced. The crystallographic parameters are listed in Table 3. In particular, $y$ is found to be lower in sample $\mathrm{Li}_{1.04} \mathrm{Ni}_{0.32} \mathrm{Mn}_{0.33} \mathrm{Co}_{0.33} \mathrm{O}_{2}$, a result in good agreement with the value obtained from analysis of magnetic measurements.

Table 3. Crystallographic parameter of $\mathrm{Li}_{1+\mathrm{x}}(\mathrm{NMC})_{1-\mathrm{x}} \mathrm{O}_{2}$ materials. $\eta_{\mathrm{R}}$ and $\eta_{\mathrm{M}}$ reveal the site-exchange rate of $\mathrm{Ni}^{2+}(3 b)$ cation mixing estimated from Rietveld refinements and magnetometry, respectively.

\begin{tabular}{cccccccc}
\hline $\mathbf{( 1 + x )}$ & $\boldsymbol{a}(\mathbf{\AA})$ & $\boldsymbol{c}(\mathbf{\AA})$ & $\boldsymbol{c l a}$ & $\boldsymbol{V}\left(\AA^{3}\right)$ & $\boldsymbol{L}(\mathbf{n m})$ & $\eta_{\mathbf{R}}(\mathbf{\%})$ & $\eta_{\mathbf{M}}(\mathbf{\%})$ \\
\hline 1.02 & $2.8650(1)$ & $14.2252(2)$ & 4.975 & $101.31(2)$ & 59.4 & 1.98 & 1.88 \\
1.04 & $2.8603(2)$ & $14.241(2)$ & 4.979 & $100.90(3)$ & 55.9 & 1.43 & 1.50 \\
\hline
\end{tabular}

Figure 10 displays the discharge capacity of the $\mathrm{Li}_{1+\mathrm{x}}(\mathrm{NMC})_{1-\mathrm{x}} \mathrm{O}_{2}$ cathode materials as a function of the cycle number with increasing discharge rate from $\mathrm{C} / 12$ to $10 \mathrm{C}$. The electrode material prepared with a Li excess of $4 \%$ exhibits the best performance at high C-rate. These electrochemical features show that the cation mixing has a slight effect on the discharge behaviour attributed to kinetic hindrance from $\mathrm{Ni}^{2+}(3 b)$ ions in the Li layer. Note the superior discharge capacity of the 333 compound compared to that of 442 one, since the increase in the Co content in NMC favours the $\mathrm{Li}^{+}$motion in the crystal lattice by improving the electronic conductivity of the electrode. In conclusion, a larger excess of lithium in the product counteracts the cation mixing (smaller value of $y$ ) and thus reduces the concentration of ferromagnetic $\mathrm{Mn}^{4+}(3 a)-\mathrm{Ni}^{2+}(3 b)$ interactions. This is actually a general trend in layered compounds, since it has been observed also in $\mathrm{Li}_{1+x}\left(\mathrm{Ni}_{0.5} \mathrm{Mn}_{0.5}\right)_{1-\mathrm{x}} \mathrm{O}_{2}$ [41]. 


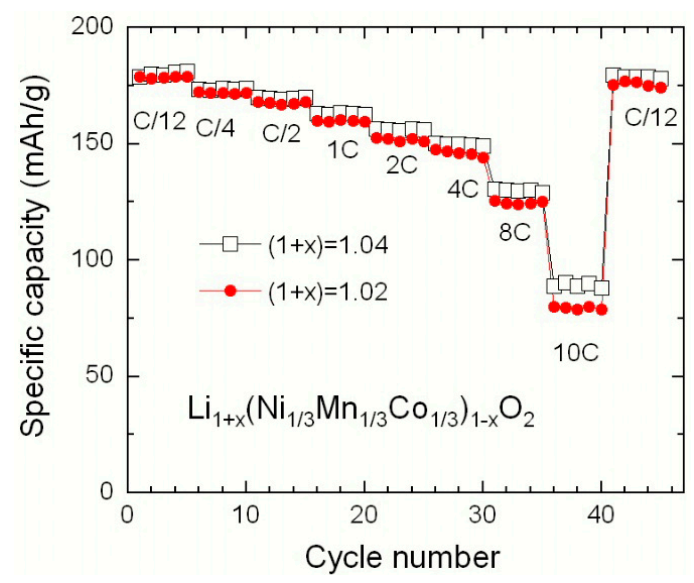

Figure 10. Electrochemical performance of $\mathrm{Li}_{1+\mathrm{x}}(\mathrm{NMC})_{1-\mathrm{x}} \mathrm{O}_{2}$ electrode materials as a function of synthetic parameters. The specific capacity of the Li cells is plotted for different C-rates.

\subsection{Effect of the Chelating Agent}

With a large amount of un-removable Ni ions in the $\mathrm{Li}(3 b)$ site that block the Li diffusion pathways, the $\mathrm{Li}^{+}$-ion mobility in the host lattice is negatively affected. For example, it was reported that the chemical diffusion coefficient of $\mathrm{Li}$ in $\mathrm{LiNi}_{0.5} \mathrm{Mn}_{0.5} \mathrm{O}_{2}$ (i.e., $3 \times 10^{-10} \mathrm{~cm}^{2} \cdot \mathrm{s}^{-1}$ ) is lower than in $\mathrm{LiCoO}_{2}$ (i.e., $5 \times 10^{-9} \mathrm{~cm}^{2} \cdot \mathrm{s}^{-1}$ ) resulting in the intrinsically low rate capability of this electrode material $[42,43]$. In this section, we investigated the effect of the transition-metal/chelating agent molar ratio, $R$ (with $0.5 \leqslant R \leqslant 5$ ) on the structural and electrochemical properties of the symmetric $333 \mathrm{NMC}$ materials synthesized by the co-precipitation method assisted by succinic acid (dicarboxyl $\mathrm{C}_{4} \mathrm{H}_{6} \mathrm{O}_{4}$ ).

The TG/DTA profiles for the mixed precursor of NMC material synthesized via $R=0.5$ are presented in Figure 11. Several weight loss stages are observed in this TG curve. The first mass loss stage occurs at $T<300^{\circ} \mathrm{C}$, which can be assigned to the loss of absorbed water, the residual ethanol, the dehydration of metal acetate, and the crystal water. The anhydrous metal acetate can be decomposed into both metal oxide and gases such as carbon mono- and di-oxide by further thermal treatment in air [13]. The weight loss in the second step is observed around $355^{\circ} \mathrm{C}$, which corresponds to the decomposition of succinic acid and acetate ions xerogel. For $R=2$, the combustion temperature has decreased to $342{ }^{\circ} \mathrm{C}$, which produces smaller crystallites. A weight loss of $72.4 \%$ occurs during these two stages because of the oxidation-decomposition reaction. It appears that tartaric acid acts as a fuel in the pyrolysis of the gel precursor, favouring the decomposition of acetate ions. After $450^{\circ} \mathrm{C}$, there is little weight loss, so in this work we choose $450{ }^{\circ} \mathrm{C}$ as the heating temperature for the pre-calcination.

Figure 12a shows the typical Rietveld fit of the XRD pattern for the sample $R=2$. The refinement was performed using the model $\left(\mathrm{Li}_{1-\delta} \mathrm{Ni}_{\delta}\right)_{3 b}\left(\mathrm{Li}_{\delta} \mathrm{Ni}_{\mathrm{x}-\delta} \mathrm{Mn}_{\mathrm{y}} \mathrm{Co}_{1-\mathrm{x}-\mathrm{y}}\right)_{3 a} \mathrm{O}_{2}$ [34]. Indeed, the concentration of $\mathrm{Ni}(3 b)$ defects and then the site-exchange rate of the $\mathrm{Li}^{+} / \mathrm{Ni}^{2+}$ cation mixing is as low as $1.26 \%$ for the $R=2$ compound, as presented in Figure 12b. With the highest $c / a$ ratio and the smallest unit volume cell, the $R=2$ sample exhibits the best layered structure. These results follow the variation of the crystallographic parameters (Table 4). The minimum of site-exchange rate corresponds to a minimum of the unit-cell volume and a maximum of degree of trigonal distortion given by the $c / a$ ratio that indicates a higher cation ordering being achieved. 


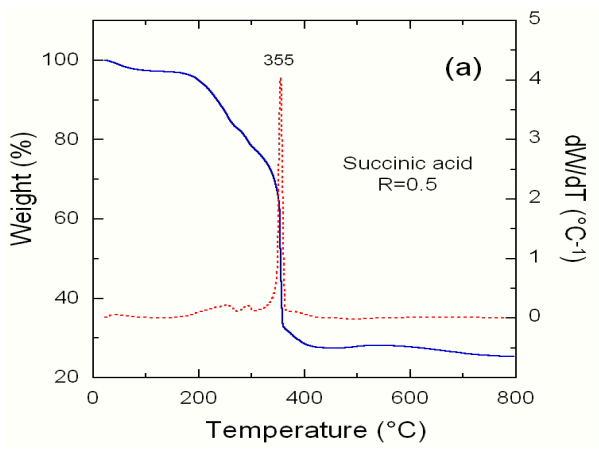

(a)

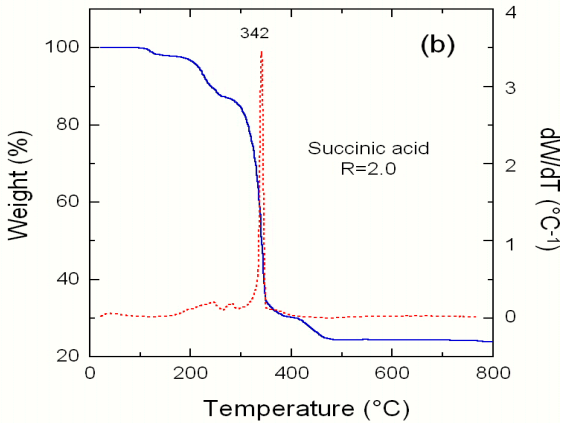

(b)

Figure 11. (a) TG/DTA profile for the precursor of NMC synthesized by the co-precipitation technique using metal acetates as raw materials and succinic acid as a polymeric agent with a chelate to metal ion molar ratio $R=0.5$ (a) and $R=2(\mathbf{b})$. With $R=2$, the combustion temperature is lowered to $342{ }^{\circ} \mathrm{C}$.
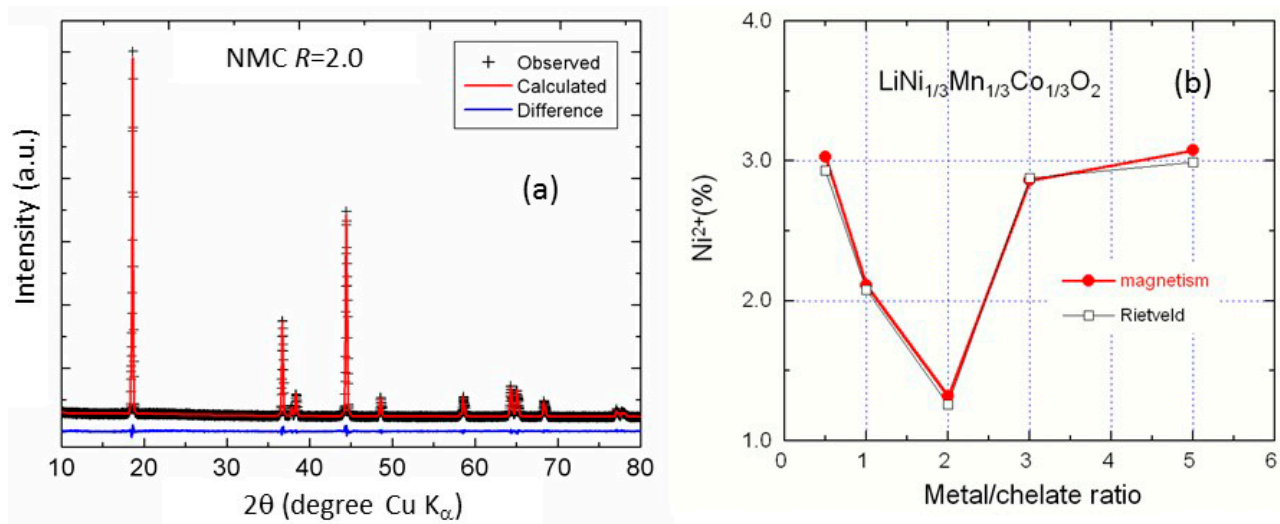

Figure 12. (a) Rietveld refinement patterns of NMC synthesized at $R=2$ via wet chemical method $\left(R_{\mathrm{p}}=9.8 \%\right)$. The plus marks show observed X-ray diffraction intensities and the solid line (in red on the web version) represents calculated intensities. The curve at the bottom (in blue on the web version) is the difference between the calculated and observed intensities on the same scale; (b) The concentration of $\mathrm{Ni}(3 b)$ defects (site-exchange rate of the $\mathrm{Li}^{+} / \mathrm{Ni}^{2+}$ cation mixing) as a function of the $R$ parameter for the symmetric NMC compounds.

Table 4. Structural data of the $\mathrm{LiNi}_{1 / 3} \mathrm{Mn}_{1 / 3} \mathrm{Co}_{1 / 3} \mathrm{O}_{2}$ samples synthesized at different values of $R$. $a, c$ are the lattice parameters, $V$ is the volume of the unit cell, and $L$ the coherence length (crystallite size). The coherence length is the arithmetic average of the length given by the Scherrer law applied to three main XRD lines. The two next lines are relative intensities of the XRD lines that provide insight on the concentration of $\mathrm{Ni}^{2+}(3 b)$ defects. The other X-ray Rietveld refinement parameters are reported in the last lines. $S\left(M_{2}\right)=2\left(1 / 3-z_{\text {oxy }}\right) c$ is the thickness of the metal- $\mathrm{O}_{2}$ planes, $I\left(\mathrm{LiO}_{2}\right)=c / 3-S\left(M_{2}\right)$ is the thickness of the interslab space; other notations are conventional.

\begin{tabular}{cccccc}
\hline Crystal Data & $\boldsymbol{R}=\mathbf{0 . 5}$ & $\boldsymbol{R}=\mathbf{1 . 0}$ & $\boldsymbol{R}=\mathbf{2 . 0}$ & $\boldsymbol{R}=\mathbf{3 . 0}$ & $\boldsymbol{R}=\mathbf{4 . 0}$ \\
\hline$a(\AA)$ & $2.8680(2)$ & $2.8671(2)$ & $2.8602(1)$ & $2.8675(2)$ & $2.8684(3)$ \\
$c(\AA)$ & $14.2588(3)$ & $14.2593(2)$ & $14.2458(2)$ & $14.2589(4)$ & $14.2619(3)$ \\
$c / a$ & $4.9716(4)$ & $4.9734(4)$ & $4.9807(2)$ & $4.9726(5)$ & $4.9720(6)$ \\
$V\left(\AA{ }^{3}\right)$ & $101.57(2)$ & $101.51(2)$ & $100.92(1)$ & $101.53(2)$ & $101.62(2)$ \\
$L(\AA)$ & $\approx 570$ & $\approx 540$ & $\approx 490$ & $\approx 550$ & $\approx 610$ \\
$I_{(003)} / I_{(104)}$ & 1.440 & 1.614 & 1.728 & 1.558 & 1.423 \\
$\left(I_{(006)}+I_{(102)}\right) / I_{(101)}$ & 0.482 & 0.427 & 0.378 & 0.438 & 0.459 \\
$S\left(\mathrm{MO}_{2}\right)(\AA)$ & $2.126(2)$ & $2.120(5)$ & $2.109(3)$ & $2.123(3)$ & $2.126(2)$ \\
$I\left(\mathrm{LiO}_{2}\right)(\AA)$ & $2.627(2)$ & $2.633(6)$ & $2.640(3)$ & $2.630(3)$ & $2.628(3)$ \\
$\eta(\%)$ & 2.96 & 2.04 & 1.26 & 2.90 & 3.0 \\
\hline \multicolumn{7}{r}{}
\end{tabular}


The study of the morphology clearly proved that the NMC synthesized with $R=2$ presents the best crystallinity, consistent with the XRD results. The chelating agent (in our case carboxylic acid) determines the acidity of the solution. The $\mathrm{R}$ value must be large enough to obtain a weak acid solution necessary to the crystallization of the oxide material. However, it must be small enough to avoid direct action with the raw materials (acetates or nitrates). That is in essence the reason why there is an optimum value for this parameter. Figure 13 displays the SEM and HRTEM images of this sample. The patterns provide evidence for the structural quality of the samples examined. Image (a) shows the representative SEM pattern of NMC powders that indicates a material containing spherical shape crystallites, as confirmed by the bright-field low-magnification TEM. Primary particles of $\sim 0.3-0.5 \mu \mathrm{m}$ size are regularly distributed. However, at a smaller scale (image b), relatively clear facets can be observed at the surface of some primary particles. The HRTEM pattern of an NMC particle (image c) shows a set of acute parallel fringes extending to the particle edge. Careful observation indicates that the fringes show a spacing distance of $0.472 \mathrm{~nm}$, which corresponds to the spacing between (003) lattice planes that diffract the $X$-rays at angle $2 \theta=18.7^{\circ}$. It is worth noting that the good morphology of the $R=2$ sample is considered to be favourable for obtaining high tap density and enhancing the electrochemical performance, i.e., improving the kinetics of lithium ions.

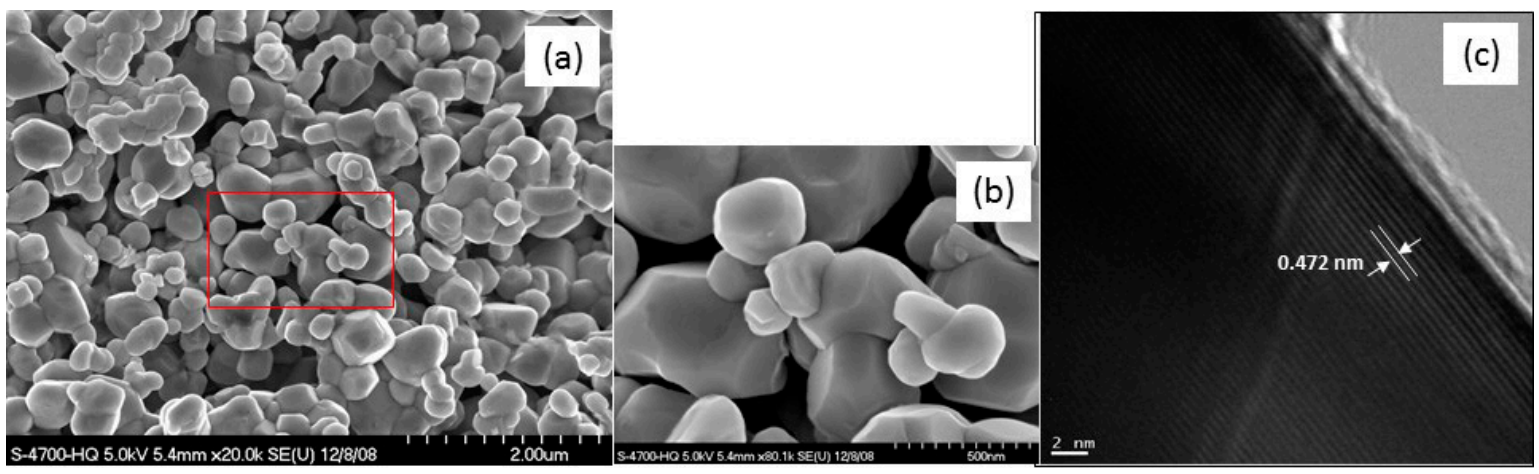

Figure 13. (a,b) SEM images of NMC synthesized at $R=2$ via wet chemical method at different magnifications; (c) HRTEM image showing the fringe system corresponding to the spacing between (003) lattice planes in the $R \overline{3} m$ space group.

Figure 14 presents the initial discharge profiles of NMC samples sintered at $900{ }^{\circ} \mathrm{C}$ for $15 \mathrm{~h}$, synthesized with an acid to metal ion ratio at $0.5 \leqslant R \leqslant 3.0$. The charge and discharge processes were carried out at a constant current density of $16 \mathrm{mAh} \cdot \mathrm{g}^{-1}(0.1 \mathrm{C}$ rate $)$ in the potential range of 2.8-4.4 V vs. $\mathrm{Li}^{0} / \mathrm{Li}^{+}$at room temperature. As expected from the structural investigations, the NMC $R=2$ material displays the best performance. Its lower cationic disorder results in its higher discharge capacity. The first charge and discharge capacity are 184 and $172 \mathrm{mAh} \cdot \mathrm{g}^{-1}$, respectively. The irreversible capacity loss in the first cycle is $12 \mathrm{mAh} \cdot \mathrm{g}^{-1}$ and the coulombic efficiency is $93.5 \%$. After four cycles, the discharge capacity is $168 \mathrm{mAh} \cdot \mathrm{g}^{-1}$ and $97.7 \%$ of the first discharge capacity has been retained. Therefore, the rather small coherence length of the lattice does not affect the good electrochemical performance. The electrochemical storage energy and intercalation mechanism in $\mathrm{NMC}$ in the potential range limited to $2.80-4.45 \mathrm{~V}$ are attributable to the $\mathrm{Ni}^{2+} / \mathrm{Ni}^{4+}$ redox reaction pair. 


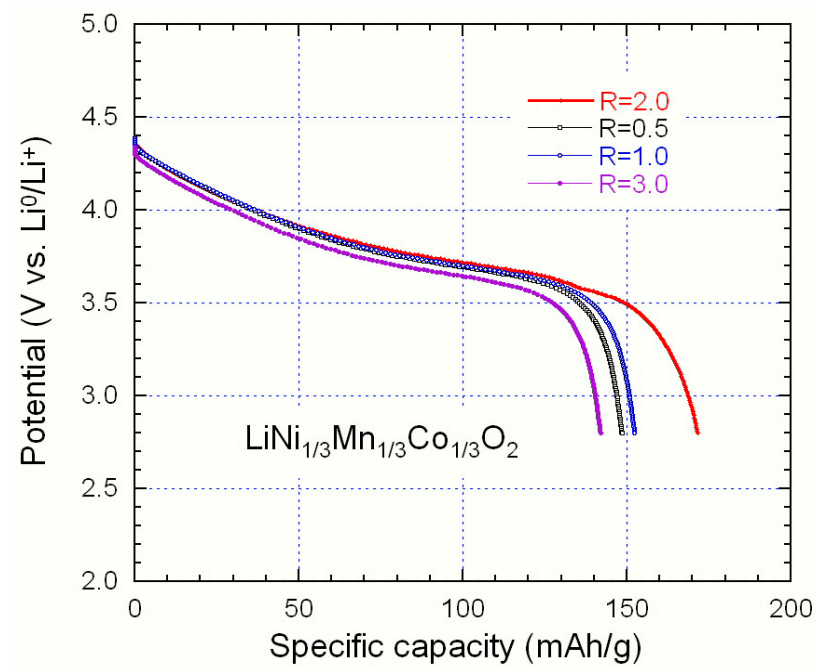

Figure 14. Initial discharge profiles of synthesized NMC sample sintered at $900{ }^{\circ} \mathrm{C}$ for $15 \mathrm{~h}$, synthesized with chelate to metal ion ratio at $0.5 \leqslant R \leqslant 3.0$.

\subsection{Effect of the Synthesis Recipe}

The synthesis parameters such as the nature of the chelating agent and the annealing temperature can strongly influence the growth process of NMC particles and thus their structure and morphology. As an example, Figure 15 presents the Peukert plots that show the difference in the electrochemical performance of $\mathrm{LiNi}_{1 / 3} \mathrm{Mn}_{1 / 3} \mathrm{Co}_{1 / 3} \mathrm{O}_{2}$ electrodes synthesized using a wet-chemical method assisted by oxalic (single dicarboxyl) and tartaric (complexed dicarboxyl) acid. It was reported that the chelating agent (carboxylic-based acid) provoked decomposition during the synthesis of oxide powders and the gel precursor was burning because the decomposed acetate ions acted as an oxidizer [44]. The wet-chemical synthesis techniques are based on the sample preparation via inorganic polymerization reactions in solution. The methods consist of an acidification reaction using organic (carboxylic) acids as complexing agents (chelate) like citric, succinic, oxalic, and tartaric acids including the - $\mathrm{COOH}$ - carboxyl groups that act as fuel during the formation process of electrode powders.

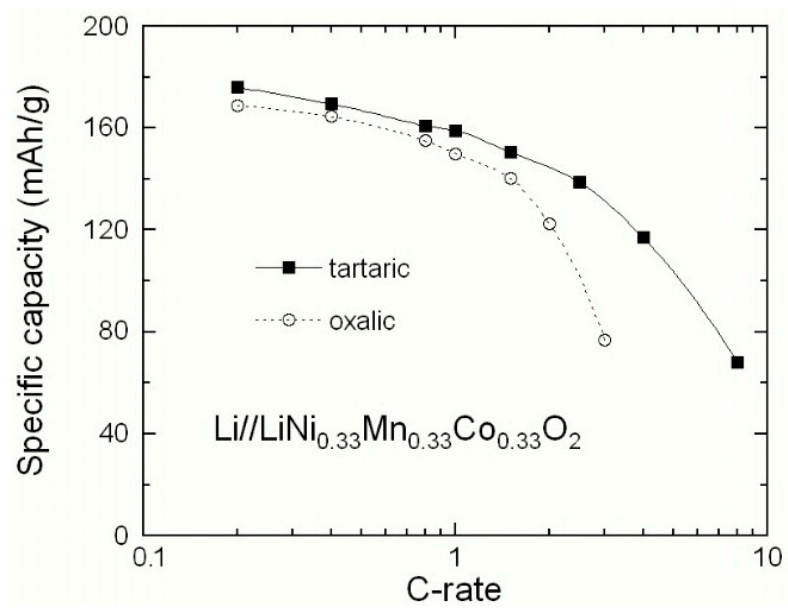

Figure 15. Peukert plots showing the difference in the electrochemical performance of $\mathrm{LiNi}_{1 / 3} \mathrm{Mn}_{1 / 3} \mathrm{Co}_{1 / 3} \mathrm{O}_{2}$ electrodes synthesized using wet-chemical method assisted by oxalic and tartaric acid.

Processing at high temperature is usually necessary to oxidize the TM ions under an oxygen atmosphere to obtain a high degree of crystallinity. However, the annealing process needs to be 
carefully conducted because high temperature favours (i) the growth of large crystallites, which is not desirable for use in high power density applications requiring nano-sized particles and (ii) a loss of lithium oxide, $\mathrm{Li}_{2} \mathrm{O}$, due to its volatility that induced sub-stoichiometric powders. Figure 16 shows the variation of the initial capacity loss of $\mathrm{LiNi}_{1 / 3} \mathrm{Mn}_{1 / 3} \mathrm{Co}_{1 / 3} \mathrm{O}_{2}$ material synthesized by the tartaric acid route as a function of the annealing temperature, $T_{\mathrm{a}}$. The electrodes were cycled at $\mathrm{C} / 20\left(\sim 10 \mathrm{~mA} \cdot \mathrm{g}^{-1}\right)$. The minimum of capacity loss is obtained for $T_{\mathrm{a}} \approx 900{ }^{\circ} \mathrm{C}$, which corresponds to an optimized particle with good crystallinity and morphology for electrode function, but also to an ordered lattice with minimum cation mixing.

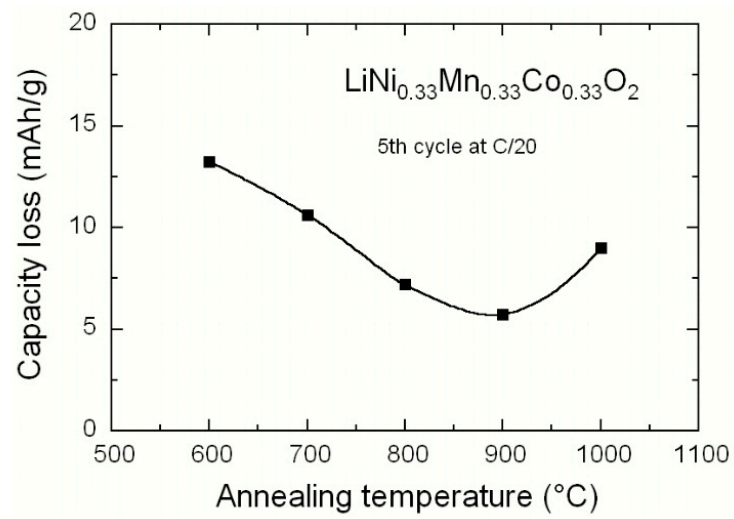

Figure 16. Initial capacity loss of $\mathrm{LiNi}_{1 / 3} \mathrm{Mn}_{1 / 3} \mathrm{Co}_{1 / 3} \mathrm{O}_{2}$ electrodes cycled at $\mathrm{C} / 20$ as a function of the annealing temperature.

\subsection{Effect of Small Deviation of Co Content}

In this section, we investigate the deviation of the local environment of cations for different compositions $\mathrm{LiNi}_{0.33+\delta} \mathrm{Mn}_{0.33+\delta} \mathrm{Co}_{0.33-2 \delta} \mathrm{O}_{2}(0.025 \leqslant \delta \leqslant 0.075)$ synthesized by sol-gel citrate route. Note that the use of citric acid (tricarboxyl) is beneficial to generate a gel instead of oxalic acid (dicarboxyl), which produces a precipitate. Single phased oxides with the typical layered rhombohedral structure were obtained after firing at $900{ }^{\circ} \mathrm{C}$ for $24 \mathrm{~h}$. Figure 17 displays the TEM images (a-c) of NMC samples with an average particle size of about $200-350 \mathrm{~nm}$, indicating that each particle is composed of a few crystallites $(<L>=70 \mathrm{~nm})$. The change of particle morphology is clearly evidenced by the TEM pictures; we observed octahedron-like $(\delta=0.025)$ and spherical like particles $(\delta=0.05$ and 0.075$)$. An HRTEM image (Figure 17d) of a NMC nanoparticle displays bright- and dark-band contrasts with widths of a few $\mathrm{nm}$. In each band contrast, there is a fringe contrast with a spacing of $0.47 \mathrm{~nm}$ that corresponds to the inter-planar spacing of the (003) hexagonal plane. The electron diffraction pattern (inset) confirms the crystallization in the $R \overline{3} m$ rhombohedral structure. The regularity in the lattice fringes implies that no dislocation is detected in the layered structure. As envisaged from our HRTEM studies, the localized domain-like features are only observed in nano-scale. The specific surface area $S_{B E T}$ slightly changed with the increasing cobalt content from 2.42 to $2.76 \mathrm{~m}^{2} \cdot \mathrm{g}^{-1}$, which confirms the particles' size evolution evidenced by TEM analysis.

Rietveld refinements of XRD patterns show that the cation mixing is lower than $2.2 \%$ in all samples owing to the stabilization of the layered structure by the cobalt. XRD results suggest that the deformation of a lattice is associated with the substitution of ( $\mathrm{Ni}, \mathrm{Mn}$ ) for Co, which is only local in nature. On another hand, this local deformation generates local strain fields that are responsible for a broadening of the XRD lines. Indeed, as the cobalt concentration decreases, the width of the XRD lines increases, so that the splitting of the (006)/(102) and (108)/(110) Bragg lines could be observed for all samples. This is not surprising since cobalt tends to stabilize the hexagonal layered structure. The deviation from stoichiometry, $\delta$, generates a strain, adding to the microscopic strain in the unit cell due to replacement of transition-metal ions in the intralayer block and to the cationic disorder, i.e., defects 
created by $\mathrm{Ni}^{2+}$ ions in the interlayer space. The profile of the Bragg lines is thus the combination of the Scherrer's equation for crystallite size and the Bragg's law for diffraction, according to the equation

$$
B^{2} \cos ^{2} \theta=16\left\langle e^{2}\right\rangle \sin ^{2} \theta+\frac{K^{2} \lambda^{2}}{L^{2}}
$$

where $B$ is the full-width at half-maximum (fwhm) in radian, $\theta$ is the diffraction angle, and $K$ is a near-unity constant related to crystallite shape. The crystallite size $L$ and micro-strain local $\left\langle e^{2}\right\rangle$ are determined by using Equation (7). Indeed, the strain $\left(\left\langle e^{2}\right\rangle\right)^{1 / 2}$ increases importantly with the stoichiometry deviation $\delta$, as shown in Figure 18. On the other hand, we find that $60 \leqslant L \leqslant 80 \mathrm{~nm}$ for all the samples, so that the replacement of cobalt does not significantly affect the coherence length. This is further evidence that the $\mathrm{LiCoO}_{2}$-like framework is disturbed by the incorporation of a great quantity of $\mathrm{Mn}$ and $\mathrm{Ni}$ ions [45].
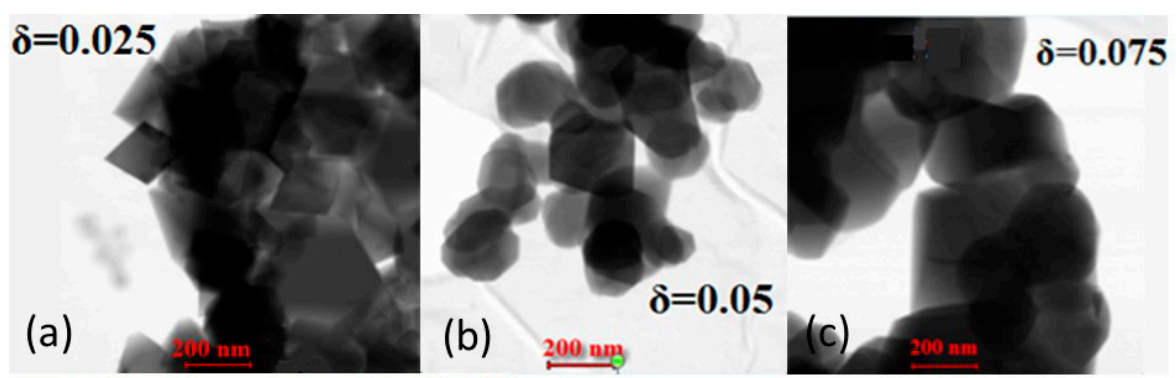

(d)

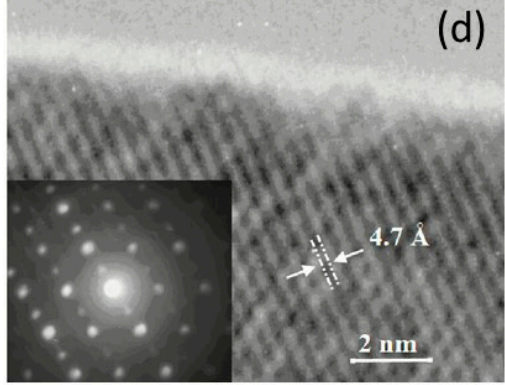

Figure 17. (a-c) TEM images of individual $\mathrm{LiNi}_{0.33+\delta} \mathrm{Mn}_{0.33+\delta} \mathrm{Co}_{0.33-2 \delta} \mathrm{O}_{2}$ nanoparticles with $\delta=0.025$, 0.05 , and 0.075 , respectively; (d) HRTEM image of a nanoparticle $(\delta=0.025)$ showing lattice fringes consistent with the interspacing of the (003) planes of the $R \overline{3} m$ layered structure.

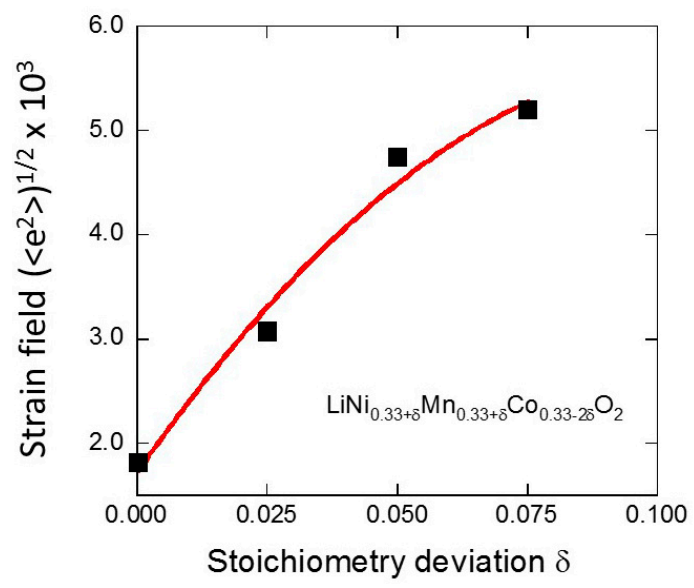

Figure 18. Evolution of the strain $\left(<e^{2}>\right)^{1 / 2}$ with the deviation from stoichiometry $\delta$ in $\mathrm{LiNi}_{0.33+\delta} \mathrm{Mn}_{0.33+\delta} \mathrm{Co}_{0.33-2 \delta} \mathrm{O}_{2}$ samples synthesized by the sol-gel method. 
As mentioned above, the electrochemical performance of materials is subordinate to the electrode microstructure and morphology. Moreover, the high crystallinity of material improves its performance because insertion and de-insertion processes occur along specific crystallographic sites and directions.

The electrochemical tests showed that the positive electrode of composition $\delta=0.025$ displays a good electrochemical performance associated with the high stability of the layered framework. The discharge capacity decreases from 210 (C/12), $150(1 \mathrm{C})$ to $69 \mathrm{mAh} \cdot \mathrm{g}^{-1}$ (10C) when cycled in the potential window $2.0-4.6 \mathrm{~V}$ vs. $\mathrm{Li}^{0} / \mathrm{Li}^{+}$, which shows that this material is well suited to develop high-powered batteries at the industrial scale for use in fast charge/discharge devices, e.g., HEV, due to its small concentration of cation mixing and high structural integrity [21]. Capacity retention of $\mathrm{CE}_{1}: 82.3 \%$ and $\mathrm{CE}_{2}: 95.2 \%$ was obtained with this electrode, which delivered a gravimetric capacity $197.8 \mathrm{mAh} \cdot \mathrm{g}^{-1}$ at $90 \% \mathrm{DOD}$ at C/5 rate. The rate performance of Li//NMC cells is depicted as Peukert plots in Figure 19. We observed a large decrease in the discharge capacity for high values of Co substitution $(\delta=0.075)$, which is related with the increasing cationic mixing [46].

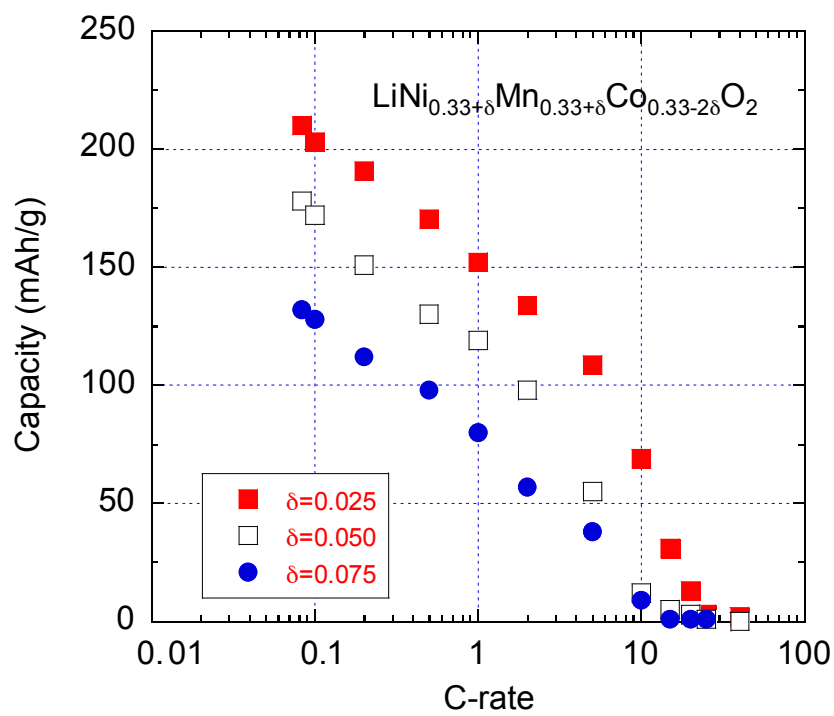

Figure 19. Peukert plots for $\mathrm{Li} / / \mathrm{LiNi}_{0.33+\delta} \mathrm{Mn}_{0.33+\delta} \mathrm{Co}_{0.33-2 \delta} \mathrm{O}_{2}$ cells.

Note in Section 3.2 the samples were prepared with $\delta=0$. Among them the (442) sample delivered discharge capacity at $\mathrm{C} / 5$ is about $170 \mathrm{mAh} \cdot \mathrm{g}^{-1}$. On the other hand, the samples in this section were prepared with $\delta \neq 0$. This is a significant difference between the 444 electrode material (Section 3.2) with the $\delta=0.075$ in the present section, which delivered only $110 \mathrm{mAh} \cdot \mathrm{g}^{-1}$ at C/5. This result confirms that the deviation of $\delta$ from zero results in a degradation of the electrochemical properties, because it induces a strain field and a local deformation of the lattice quantified in Figure 18.

\subsection{Layered-Layered Integrated Materials}

In order to meet the demand for high energy density batteries, it is necessary to develop high-capacity cathode materials that are safe and present good electrochemical performance. For such a purpose, Li-rich oxides with the layered-layered integrated (LLL) configuration of composition $y \mathrm{Li}_{2} \mathrm{MnO}_{3} \bullet(1-y) \mathrm{LiMO}_{2}$, where $M$ stands for Mn or a mixture of Mn with another transition metal that can be partially substituted for Mn, are of particular interest. The LLI materials have been the subject of extensive works that have been reviewed in [47]. However many problems still have to be solved. Current debates on structure and reaction mechanism, problems on electrochemical properties, and keys to the future study of these materials have been reviewed by Yu and Zhou [48].

In the following, we report experiments on $\mathrm{Li}\left(\mathrm{Ni}_{\mathrm{x}} \mathrm{Li}_{(1 / 3-2 \mathrm{x} / 3)} \mathrm{Mn}_{(2 / 3-x / 3)}\right) \mathrm{O}_{2}$, which can be rewritten in two-component notation as $y \mathrm{Li}_{2} \mathrm{MnO}_{3} \bullet(1-y) \mathrm{LiNi}_{\frac{1}{2}} \mathrm{Mn}_{\frac{1}{2}} \mathrm{O}_{2}$; it offers several advantages over 
conventional cathode materials: a specific capacity as high as $250 \mathrm{mAh} \cdot \mathrm{g}^{-1}$, good structural stability, and high capacity retention at high voltage cutoff [49]. The choice of Ni doping is justified by the fact that $\mathrm{Ni}$ plays a positive role in the $\mathrm{O}^{2-}$ ions' oxidation to $\mathrm{O}_{2}$ [50]. By extracting the $\mathrm{Li}$ ions with a concomitant oxygen release to form a layered $\mathrm{MnO}_{2}$ component at ca. $4.6-4.8 \mathrm{~V} \mathrm{vs.} \mathrm{Li}^{0} / \mathrm{Li}^{+}$, the $\mathrm{Li}_{2} \mathrm{MnO}_{3}$ component is considered to have two functions: (i) the stabilization of the electrode structure and (ii) the enhancement of the discharge capacity. In this section we report the study of $y \mathrm{Li}_{2} \mathrm{MnO}_{3} \bullet(1-y)\left(\mathrm{LiNi}_{0.5} \mathrm{Mn}_{0.5} \mathrm{O}_{2}\right)$ samples with $y=0.0,0.3$ and 0.5 synthesized by citrate sol-gel method. These oxides are commonly viewed as integrated composites of layered $\mathrm{Li}_{2} \mathrm{MnO}_{3}$ with monoclinic $C / 2 m$ symmetry and layered $\mathrm{LiNi}_{0.5} \mathrm{Mn}_{0.5} \mathrm{O}_{2}$ with rhombohedral $R \overline{3} m$ symmetry.

Figure 20 shows the morphology of the LLL samples with $y=0.0,0.3$, and 0.5 synthesized by a citrate-gel method using acetate salts. These TEM images reveal highly ordered single crystalline particles with regular shape and morphology for all the samples. All the powders consist of primary particles smaller than $500 \mathrm{~nm}$. The particles of the $\mathrm{Li}_{1.134} \mathrm{Ni}_{0.3} \mathrm{Mn}_{0.566} \mathrm{O}_{2}$ sample are smaller in size $(\sim 150 \mathrm{~nm})$ and nearly monodisperse; however, a slight tendency to agglomerate is observed by SEM measurements (not shown here). The HRTEM micrograph (image d) shows that the $\mathrm{Li}_{1.2} \mathrm{Ni}_{0.2} \mathrm{Mn}_{0.6} \mathrm{O}_{2}$ powders are formed of well-crystallized hexagonal-shaped particles. The crystal faces are well defined and the distribution of particles is uniform.
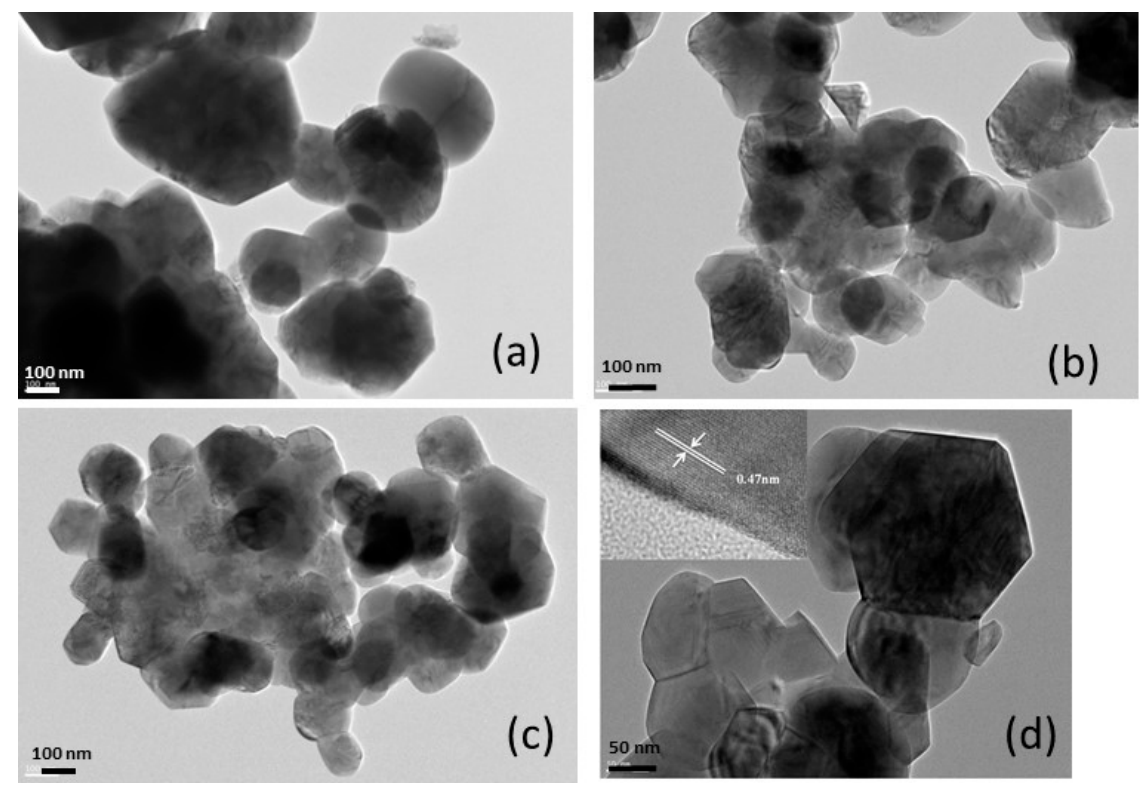

Figure 20. HRTEM images of Li-rich cathode materials $y \mathrm{Li}_{2} \mathrm{MnO}_{3} \bullet(1-y)\left(\mathrm{LiNi}_{0.5} \mathrm{Mn}_{0.5} \mathrm{O}_{2}\right)$. (a) $y=0.0\left(\mathrm{LiNi}_{0.5} \mathrm{Mn}_{0.5} \mathrm{O}_{2}\right)$; (b) $y=0.3\left(\mathrm{Li}_{1.134} \mathrm{Ni}_{0.3} \mathrm{Mn}_{0.566} \mathrm{O}_{2}\right)$; (c) $y=0.5\left(\mathrm{Li}_{1.2} \mathrm{Ni}_{0.2} \mathrm{Mn}_{0.6} \mathrm{O}_{2}\right)$; (d) image magnification for $\mathrm{Li}_{1.2} \mathrm{Ni}_{0.2} \mathrm{Mn}_{0.6} \mathrm{O}_{2}$ showing the hexagonal shape of nanoparticles.

In the inset (image d), one observes well-defined fringes corresponding to the typical $\alpha-\mathrm{NaFeO}_{2}$ layered structure with interplanar distance of about $0.47 \mathrm{~nm}$, which is the distance of the close-packed (003) planes of the rhombohedral $R \overline{3} m$ lattice (or the (001) planes of the monoclinic $C 2 / m$ lattice). These fringes are observed over the whole region, which means that the pure single layered structured phase is built up throughout the careful synthesis recipe of wet chemistry. Analysis of XRD patterns show that the $c_{\mathrm{h}} / a_{\mathrm{h}}$ ratio increases linearly with the Li concentration. This effect is attributable to the increase of concentration of $\mathrm{Mn}^{4+}$ ions, the ionic radius of which $(0.54 \AA)$ is smaller than that of $\mathrm{Ni}^{2+}$ $(0.69 \AA)$ in octahedral coordination.

Figure 21 presents the electrochemical tests of $\mathrm{Li} / / \mathrm{Li}\left(\mathrm{Ni}_{\mathrm{x}} \mathrm{Li}_{(1 / 3-2 \mathrm{x} / 3)} \mathrm{Mn}_{(2 / 3-\mathrm{x} / 3)}\right) \mathrm{O}_{2}$ coin cells cycled at $\mathrm{C} / 10$ rate $\left(30 \mathrm{~mA} \cdot \mathrm{g}^{-1}\right)$ in the potential range $2.0-4.8 \mathrm{~V}$ vs. $\mathrm{Li}^{0} / \mathrm{Li}^{+}$. The initial discharge capacity of the $\mathrm{LiNi}_{0.5} \mathrm{Mn}_{0.5} \mathrm{O}_{2}$ electrode is approximately $181 \mathrm{mAh} \cdot \mathrm{g}^{-1}$ with a capacity 
loss of $39 \mathrm{mAh} \cdot \mathrm{g}^{-1}$, while high discharge capacities of 230 and $253 \mathrm{mAh} \cdot \mathrm{g}^{-1}$ are obtained for $\mathrm{Li}_{1.134} \mathrm{Ni}_{0.3} \mathrm{Mn}_{0.556} \mathrm{O}_{2}$ and $\mathrm{Li}_{1.2} \mathrm{Ni}_{0.2} \mathrm{Mn}_{0.6} \mathrm{O}_{2}$ samples, respectively. Upon increasing the lithium enrichment, the coulombic efficiency after the 2nd cycle slightly increases from $98.6 \%$ to $99.5 \%$. On the contrary, the irreversible capacity loss in the first cycle slightly increases from 20 to $23 \mathrm{mAh} \cdot \mathrm{g}^{-1}$ with the Li-rich oxides, i.e., $\mathrm{Li}_{1.134} \mathrm{Ni}_{0.3} \mathrm{Mn}_{0.556} \mathrm{O}_{2}$ and $\mathrm{Li}_{1.2} \mathrm{Ni}_{0.2} \mathrm{Mn}_{0.6} \mathrm{O}_{2}$, respectively. For all the cells, the first irreversible capacity associated with the high voltage plateau is due to the activation of the $\mathrm{Li}_{2} \mathrm{MnO}_{3}$ component with extraction of lithium and oxygen release at approximately $4.5 \mathrm{~V}$. For subsequent cycles their coulombic efficiency is stabilized, in contrast with the behaviour of the $\mathrm{LiNi}_{0.5} \mathrm{Mn}_{0.5} \mathrm{O}_{2}$ electrode. The potential profiles show that the initial discharge capacity located in the range $230-260 \mathrm{mAh} \cdot \mathrm{g}^{-1}$ is retained at $200-220 \mathrm{mAh} \cdot \mathrm{g}^{-1}$ after 30 cycles, while the stoichiometric compound $\mathrm{LiNi}_{0.5} \mathrm{Mn}_{0.5} \mathrm{O}_{2}$ only displays an initial discharge capacity of $180 \mathrm{mAh} \cdot \mathrm{g}^{-1}$.
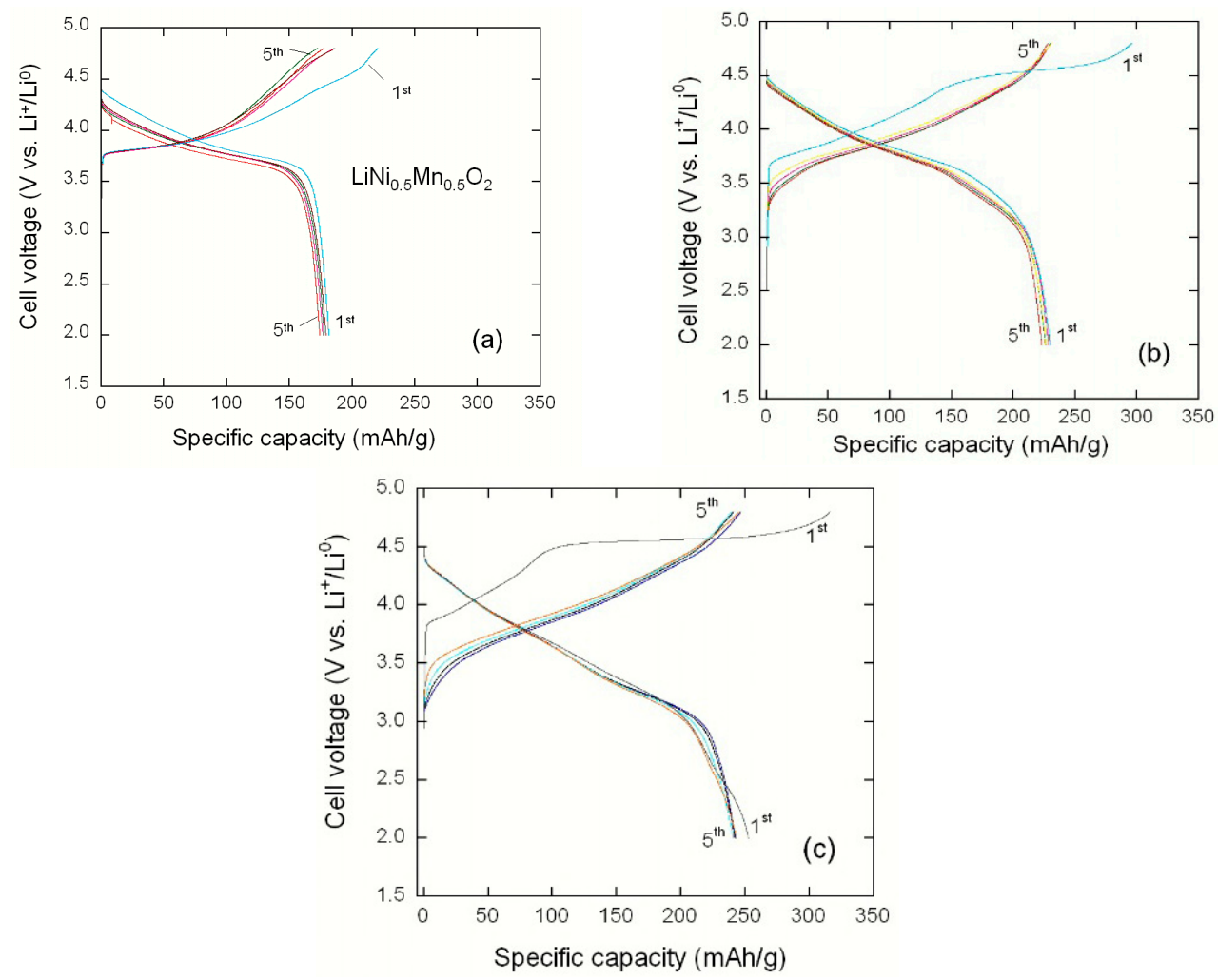

Figure 21. Charge-discharge profiles of $\mathrm{Li} / / \mathrm{Li}_{(}\left(\mathrm{Ni}_{x} \mathrm{Li}_{(1 / 3-2 \times / 3)} \mathrm{Mn}_{(2 / 3-x / 3)}\right) \mathrm{O}_{2}$ coin cells: (a) $\mathrm{LiNi}_{0.5} \mathrm{Mn}_{0.5} \mathrm{O}_{2} ;$ (b) $\mathrm{Li}_{1.134} \mathrm{Ni}_{0.3} \mathrm{Mn}_{0.556} \mathrm{O}_{2}$; and (c) $\mathrm{Li}_{1.2} \mathrm{Ni}_{0.2} \mathrm{Mn}_{0.6} \mathrm{O}_{2}$. Cycles were carried out at $\mathrm{C} / 10$ rate $\left(30 \mathrm{~mA} \cdot \mathrm{g}^{-1}\right)$ in the potential range $2.0-4.8 \mathrm{Vvs.} \mathrm{Li}^{0} / \mathrm{Li}^{+}$.

The charge-discharge reactions of a Li-rich electrode are described by the activation of the two components $\mathrm{LiNi}_{0.5} \mathrm{Mn}_{0.5} \mathrm{O}_{2}$ and $\mathrm{Li}_{2} \mathrm{MnO}_{3}$ as follows [51]. Let us consider the case of $\mathrm{Li}_{1.2} \mathrm{Ni}_{0.2} \mathrm{Mn}_{0.6} \mathrm{O}_{2}$, otherwise written as $0.5 \mathrm{Li}_{2} \mathrm{MnO}_{3} \bullet 0.5 \mathrm{LiNi}_{0.5} \mathrm{Mn}_{0.5} \mathrm{O}_{2}$.

(1) First step of charge reaction by activation of the $R \overline{3} m$ phase with a regular $\mathrm{Li}^{+}$extraction from the $3 b$ site of the layered lattice:

$$
0.5 \mathrm{Li}_{2} \mathrm{MnO}_{3} \bullet 0.5 \mathrm{LiNi}_{0.5} \mathrm{Mn}_{0.5} \mathrm{O}_{2} \rightarrow 0.5 \mathrm{Li}_{2} \mathrm{MnO}_{3} \bullet 0.5 \mathrm{Li}_{0.5} \mathrm{Ni}_{0.5} \mathrm{Mn}_{0.5} \mathrm{O}_{2}+0.5 \mathrm{Li}^{+}+0.5 \mathrm{e}^{-}
$$

(2) Second step of charge reaction by activation of $\mathrm{Li}_{2} \mathrm{MnO}_{3}$ inducing loss of $\mathrm{Li}$ and oxygen release at the end of the charge i.e., potential above $4.5 \mathrm{~V}$ : 
(3) Discharge process by the insertion of the $R \overline{3} m$ phase and formation of the new $\mathrm{LiMnO}_{2}$ lithiated phase:

$(0.5-\alpha) \mathrm{Li}_{2} \mathrm{MnO}_{3} \bullet \alpha \mathrm{MnO}_{2} \bullet 0.5 \mathrm{Li}_{0.5} \mathrm{Ni}_{0.5} \mathrm{Mn}_{0.5} \mathrm{O}_{2}+(0.5+\alpha) \mathrm{Li}^{+}+(0.5+\alpha) \mathrm{e}^{-} \rightarrow(0.5-\alpha) \mathrm{Li}_{2} \mathrm{MnO}_{3} \bullet \alpha \mathrm{LiMnO}_{2} \bullet 0.5 \mathrm{LiNi}_{0.5} \mathrm{Mn}_{0.5} \mathrm{O}_{2}$.

Figure 22 illustrates the first charge-discharge profile of a $\mathrm{Li} / / \mathrm{Li}_{1.2} \mathrm{Ni}_{0.2} \mathrm{Mn}_{0.6} \mathrm{O}_{2}$ cell cycled at $\mathrm{C} / 10$, showing the mechanism of the activation of $\mathrm{Li}_{2} \mathrm{MnO}_{3}$ and $\mathrm{LiNi}_{0.5} \mathrm{Mn}_{0.5} \mathrm{O}_{2}$ components. The typical features of the $\mathrm{Li} / / \mathrm{Li}\left(\mathrm{Ni}_{x} \operatorname{Li}_{(1 / 3-2 x / 3)} \mathrm{Mn}_{(2 / 3-x / 3)}\right) \mathrm{O}_{2}$ coin cells cycled at $\mathrm{C} / 10$ in the voltage range $2.0-4.8 \mathrm{~V} \mathrm{vs} . \mathrm{Li}^{0} / \mathrm{Li}^{+}$are shown in Figure 23. With an initial discharge capacity of $252.8 \mathrm{mAh} \cdot \mathrm{g}^{-1}$, this electrode, $\mathrm{Li}_{1.2} \mathrm{Ni}_{0.2} \mathrm{Mn}_{0.6} \mathrm{O}_{2}$, appears to be the best among the studied materials. The capacity decreased slightly upon cycling at the rate of $1.01 \mathrm{mAh} \cdot \mathrm{g}^{-1}$ per cycle. These results are comparable to those in the literature [52-54]. Liu et al. [53] reported a discharge capacity $253 \mathrm{mAh} \cdot \mathrm{g}^{-1}$ for $\mathrm{MnO}_{2}$-coated $\mathrm{Li}_{1.2} \mathrm{Ni}_{0.2} \mathrm{Mn}_{0.6} \mathrm{O}_{2}$ cycled at $\mathrm{C} / 10$. Zhao et al. [54] showed that the same electrode materials doped with Sn delivered a lower initial discharge capacity of $212.6 \mathrm{mAh} \cdot \mathrm{g}^{-1}$, which seems to be due to the formation of big secondary particles synthesized via a carbonate co-precipitation method.

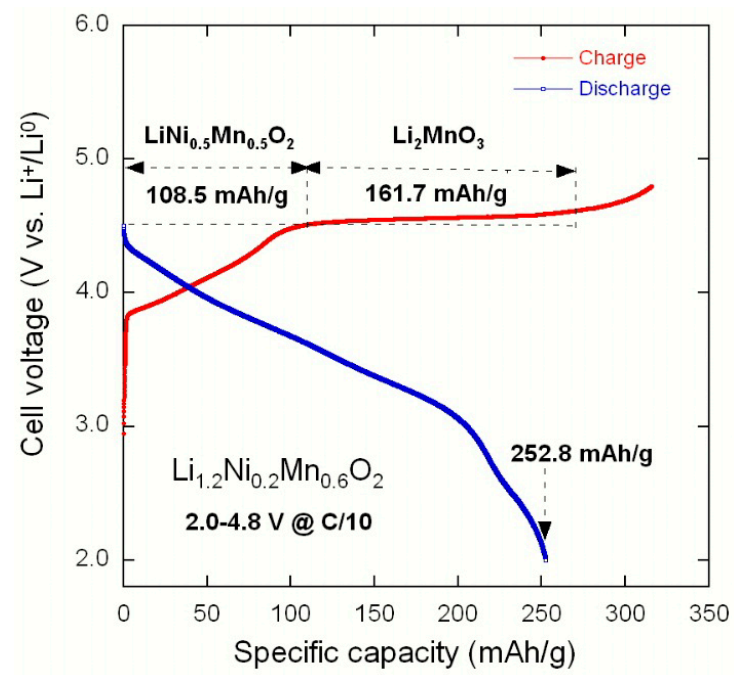

Figure 22. The first charge-discharge profile of a $\mathrm{Li} / / \mathrm{Li}_{1.2} \mathrm{Ni}_{0.2} \mathrm{Mn}_{0.6} \mathrm{O}_{2}$ cell cycled at $\mathrm{C} / 10$, showing the mechanism of the activation of $\mathrm{Li}_{2} \mathrm{MnO}_{3}$ and $\mathrm{LiNi}_{0.5} \mathrm{Mn}_{0.5} \mathrm{O}_{2}$ components.

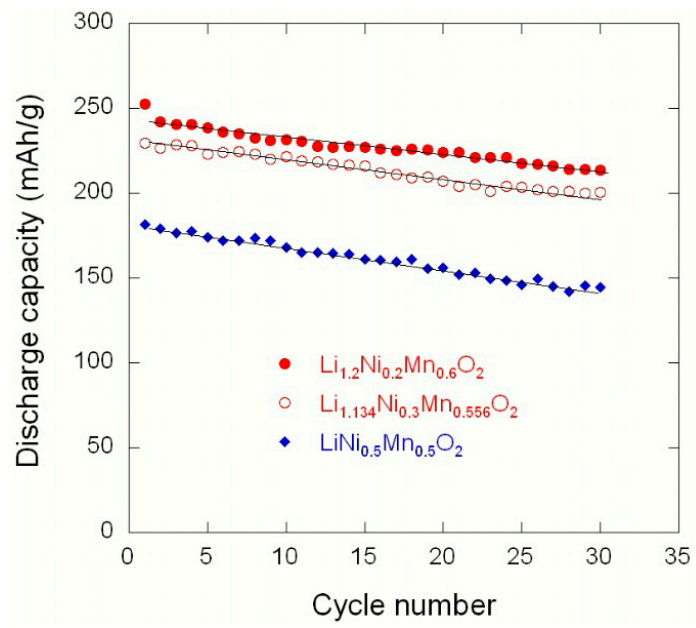

Figure 23. Cyclic performance of $\mathrm{Li} / / \mathrm{Li}\left(\mathrm{Ni}_{\mathrm{x}} \mathrm{Li}_{(1 / 3-2 \mathrm{x} / 3)} \mathrm{Mn}_{(2 / 3-x / 3)}\right) \mathrm{O}_{2}$ electrodes at $\mathrm{C} / 10$. 
According to Figure 23, we find here that the Ni doping has improved the capacity but it had no effect on the cycling stability, since the slope of the capacity as a function of the cycle number is the same for the different compositions. This is in contrast with prior conclusions of Lu et al., who found that the cycling stability was significantly enhanced in samples with $x>1 / 4$ in $\mathrm{Li}\left(\mathrm{Ni}_{x} \mathrm{Li}_{1 / 3-2 x / 3} \mathrm{Mn}_{2 / 3-x / 3}\right) \mathrm{O}_{2}$ [55-57]. Indeed, the stability of the Li-rich materials is the main problem that still has to be solved before any application can be envisioned [58-62]. The characterization of a $0.5 \mathrm{Li}_{2} \mathrm{MnO}_{3} \cdot 0.5 \mathrm{LiMn}_{0.42} \mathrm{Ni}_{0.42} \mathrm{Co}_{0.16} \mathrm{O}_{2}$ "composite" by the synchrotron X-ray powder diffraction has shown complex reaction pathways that depend on the current density [63]. As the Li content relative to $\mathrm{Ni}$ and $\mathrm{Mn}$ decreased, the LLL materials were observed to be either single-phase layered, two-phase layered-rocksalt, or three-phase layered-rocksalt-spinel, depending on their location within the Li-Mn-Ni-O phase diagram [64]. Gu et al. have shown that, upon 300 cycles of charge/discharge, the structure of $\mathrm{Li}_{1.2} \mathrm{Ni}_{0.2} \mathrm{Mn}_{0.6} \mathrm{O}_{2}$ is transformed into a spinel structure [65]. Therefore, the evolution of the LLLs and their related degradation upon cycling is a complex problem that is not entirely understood-in contrast with the NMC case, where the delithiation proceeds in two well-identified steps in $\mathrm{Li}_{\mathrm{x}} \mathrm{Ni}_{\mathrm{y}} \mathrm{Mn}_{\mathrm{y}} \mathrm{Co}_{1-2 \mathrm{y}} \mathrm{O}_{2}$ : the first step of the delithiation is associated with the redox reaction involving the nickel ions: $\mathrm{Ni}^{2+} \rightarrow \mathrm{Ni}^{3+} \rightarrow \mathrm{Ni}^{4+}$ in the composition range $1>x>1-2 y$; the second step is the redox process $\mathrm{Co}^{3+} \rightarrow \mathrm{Co}^{4+}$ in the range $x<1-2 y$, as there is practically no overlap between the two redox reactions [38].

\section{Concluding Remarks}

In this work we have examined several cathode materials for Li-ion batteries, all of them crystallizing in a layered network. The effect of the synthesis procedure on the cationic distribution in NMC compounds with various configurations and the merit of the hierarchical nano-/micro-structures was investigated. The local $\mathrm{Ni}^{2+}$ arrangement on the lithium layers has been estimated as a function of the composition, the $\mathrm{Li} /$ metal ratio, and the metal/chelating agent used in the sample preparation. It has been demonstrated that the high crystallinity is essential to obtain accurate electrochemical performance and to maintain the structural integrity of the electrode lattice during cycling. Among the mixed transition metal oxides, $\mathrm{Li}_{1 / 3} \mathrm{Ni}_{1 / 3} \mathrm{Mn}_{1 / 3} \mathrm{CoO}_{2}$ appears to be an attractive material because the combination of $\mathrm{Ni}, \mathrm{Mn}$, and $\mathrm{Co}$ can provide many advantages such as high specific capacity compared with $\mathrm{LiCoO}_{2}$. Its good structural integrity is due to the absence of $\mathrm{Mn}^{3+} \mathrm{Jahn}-\mathrm{Teller}$ ions. Both Rietveld refinements and magnetic measurements have shown that the $\mathrm{Li} / \mathrm{Ni}$ cation mixing on the $3 b$ Wyckoff site of the interslab space was very small (concentration of $\mathrm{Ni}^{2+}-3 b$ ions lower than $2 \%)$ and consistent with the structural model $\left(\mathrm{Li}_{1-\delta} \mathrm{Ni}_{\delta}\right)_{3 b}\left(\mathrm{Li}_{\delta} \mathrm{Ni}_{\mathrm{x}-\delta} \mathrm{Mn}_{\mathrm{y}} \mathrm{Co}_{1-\mathrm{x}-\mathrm{y}}\right)_{3 a} \mathrm{O}_{2}$ results obtained by adjusting parameters of synthesis. Electrochemical tests carried out by galvanostatic charge-discharge cycling reflected the high degree of sample optimization.

A significant increase in the specific capacity was obtained with $\mathrm{Li}_{2} \mathrm{MnO}_{3}$ and $\mathrm{LiNi}_{0.5} \mathrm{Mn}_{0.5} \mathrm{O}_{2}$

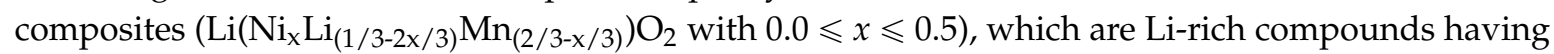
an intergrown structure (or integrated layered-layered). Their specific capacity reached $200 \mathrm{mAh} \cdot \mathrm{g}^{-1}$ after 30 cycles or more. However, while the mechanism of the lithiation-delithiation process is well understood in NMC materials, which in addition is reversible, that of the Li-rich compounds is still under debate and the problem of degradation upon cycling is not yet solved. The rate capability is a problem that seems more difficult to overcome. $\mathrm{Li}_{1.2} \mathrm{Ni}_{0.2} \mathrm{Mn}_{0.6} \mathrm{O}_{2}$ core encapsulated by a nanospinel $\left(\mathrm{LiNi}_{\mathrm{x}} \mathrm{Mn}_{2-\mathrm{x}} \mathrm{O}_{4}\right)$ layer with the thickness of about $10 \mathrm{~nm}$ combined the advantages of the highly conductive spinel surface and high capacity layered core was able to deliver $274.6 \mathrm{mAh} \cdot \mathrm{g}^{-1}$ at $1 \mathrm{C}$ rate [61]. Song et al. used graphene oxide (GO) to wrap their $\mathrm{Li}\left(\mathrm{Li}_{0.2} \mathrm{Mn}_{0.54} \mathrm{Ni}_{0.13} \mathrm{Co}_{0.13}\right) \mathrm{O}_{2}$ material [66]. In addition to the highly conductive cubic spinel transformed from the layered phase on the surface during electrochemical cycling [67], the graphene oxide was also reduced. As a result, this composite delivered $201 \mathrm{mAh} \cdot \mathrm{g}^{-1}$ at a current density of $2500 \mathrm{~mA} \cdot \mathrm{g}^{-1}$. However, even if coating the LLL particles with different materials improves the capacity retention, none of them is currently able to prevent the degradation upon many cycles. This is thus the main problem that remains to be solved, 
together with the voltage decay of LLLs over a long period of cycling, before these promising materials can find an industrial development.

Acknowledgments: The authors are grateful to Xiaoyu Zhang, Ashraf Abdel-Ghany, and Nourredine Amdouni, Julie Trottier, and René Veillette for their technical assistance in sample preparation, electrochemical measurements, and HRTEM imaging.

Author Contributions: Writing of the manuscript was done by Christian Julien and Alain Mauger. Supervision of the experimental works was performed by Karim Zaghib and Henri Groult.

Conflicts of Interest: The authors declare no conflict of interest.

\section{References}

1. Julien, C.M.; Mauger, A.; Vijh, A.; Zaghib, K. Lithium Batteries: Science and Technology; Springer: Heidelberg, Germany, 2015; p. 630.

2. Julien, C.M.; Mauger, A.; Zaghib, K.; Groult, H. Comparative issues of cathode materials for Li-ion batteries. Inorganics 2014, 2, 132-154. [CrossRef]

3. Zaghib, K.; Mauger, A.; Groult, H.; Goodenough, J.B.; Julien, C.M. Advanced electrode of high-power Li-ion batteries. Materials 2013, 6, 1028-1049. [CrossRef]

4. Fergus, J.W. Recent developments in cathode materials for lithium ion batteries. J. Power Sources 2010, 195, 939-954. [CrossRef]

5. Mauger, A.; Julien, C.M. Nanoscience supporting the research on the negative electrodes of Li-ion batteries. Nanomaterials 2015, 5, 2279-2301. [CrossRef]

6. Vediappan, K.; Guerfi, A.; Gariépy, V.; Demopoulos, G.P.; Hovington, P.; Trottier, J.; Mauger, A.; Zaghib, K.; Julien, C.M. Stirring effect in hydrothermal synthesis of C-LiFePO . J. Power Sources 2014, 266, 99-106. [CrossRef]

7. Hovington, P.; Lagacé, M.; Guerfi, A.; Bouchard, P.; Mauger, A.; Julien, C.M.; Armand, M.; Zaghib, K. New lithium metal polymer solid state battery for an ultrahigh energy: Nano C-LiFePO versus nano $\mathrm{Li}_{1.2} \mathrm{~V}_{3} \mathrm{O}_{8}$. Nano Lett. 2015, 15, 2671-2678. [CrossRef] [PubMed]

8. Liu, Z.; Yu, A.; Lee, J.Y. Synthesis and characterization of $\mathrm{LiNi}_{1-\mathrm{x}-\mathrm{y}} \mathrm{Co}_{\mathrm{x}} \mathrm{Mn}_{\mathrm{y}} \mathrm{O}_{2}$ as the cathode materials of secondary lithium batteries. J. Power Sources 1999, 81-82, 416-419. [CrossRef]

9. Ohzuku, T.; Makimura, Y. Layered lithium insertion material of $\mathrm{LiCo}_{1 / 3} \mathrm{Ni}_{1 / 3} \mathrm{Mn}_{1 / 3} \mathrm{O}_{2}$ for lithium-ion batteries. Chem. Mater. 2001, 30, 642-643. [CrossRef]

10. MacNeil, D.D.; Lu, Z.; Dahn, J.R. Structure and electrochemistry of $\operatorname{Li}\left(\mathrm{Ni}_{\mathrm{x}} \mathrm{Co}_{1-2 \mathrm{x}} \mathrm{Mn}_{\mathrm{x}}\right) \mathrm{O}_{2}(0 \leqslant x \leqslant 1 / 2)$. J. Electrochem. Soc. 2002, 149, A1332-A1336. [CrossRef]

11. Yabuuchi, N.; Ohzuku, T. Novel lithium insertion material of $\mathrm{Li}\left(\mathrm{Co}_{1 / 3} \mathrm{Ni}_{1 / 3} \mathrm{Mn}_{1 / 3}\right) \mathrm{O}_{2}$ for advanced lithium-ion batteries. J. Power Sources 2003, 119, 171-174. [CrossRef]

12. Belharouak, I.; Sun, Y.K.; Liu, J.; Amine, $\mathrm{K}$. $\mathrm{Li}\left(\mathrm{Ni}_{1 / 3} \mathrm{Co}_{1 / 3} \mathrm{Mn}_{1 / 3}\right) \mathrm{O}_{2}$ as a suitable cathode for high power applications. J. Power Sources 2003, 123, 247-252. [CrossRef]

13. Zhang, X.; Mauger, A.; Lu, Q.; Groult, H.; Perrigaud, L.; Gendron, F.; Julien, C.M. Synthesis and characterization of $\mathrm{LiNi}_{1 / 3} \mathrm{Mn}_{1 / 3} \mathrm{Co}_{1 / 3} \mathrm{O}_{2}$ by wet-chemical method. Electrochim. Acta 2010, 55, 6440-6449. [CrossRef]

14. Shaju, K.M.; Subba Rao, G.V.; Chowdari, B.V.R. Performance of layered $\mathrm{Li}\left(\mathrm{Ni}_{1 / 3} \mathrm{Co}_{1 / 3} \mathrm{Mn}_{1 / 3}\right) \mathrm{O}_{2}$ as cathode for Li-ion batteries. Electrochim. Acta 2002, 48, 145-151. [CrossRef]

15. Kim, J.M.; Chung, H.T. The first cycle characteristics of $\mathrm{Li}\left(\mathrm{Ni}_{1 / 3} \mathrm{Mn}_{1 / 3} \mathrm{Co}_{1 / 3}\right) \mathrm{O}_{2}$ charged up to $4.7 \mathrm{~V}$. Electrochim. Acta 2004, 49, 937-944. [CrossRef]

16. Goodenough, J.B.; Kim, Y. Challenges for rechargeable Li batteries. Chem. Mater. 2010, 22, 587-603. [CrossRef]

17. Song, C.H.; Stephan, A.M.; Kim, A.; Nahm, K.S. Influence of solvents on the structural and electrochemical properties of $\mathrm{Li}\left(\mathrm{Li}_{0.2} \mathrm{Ni}_{0.1} \mathrm{Co}_{0.2} \mathrm{Mn}_{0.5}\right) \mathrm{O}_{2}$ prepared by a solvothermal reaction method. J. Electrochem. Soc. 2006, 153, A390-A395. [CrossRef]

18. Julien, C.; El-Farh, L.; Rangan, S.; Massot, M. Studies of $\mathrm{LiNi}_{0.6} \mathrm{Co}_{0.4} \mathrm{O}_{2}$ cathode material prepared by the citric acid-assisted sol-gel method for lithium batteries. J. Sol-Gel Sci. Technol. 1999, 15, 63-72. [CrossRef]

19. Julien, C.; Letranchant, C.; Rangan, S.; Lemal, M.; Ziolkiewicz, S.; Castro-Garcia, S.; El-Farh, L.; Benkaddour, M. Layered $\mathrm{LiNi}_{0.5} \mathrm{Co}_{0.5} \mathrm{O}_{2}$ cathode materials grown by soft-chemistry via various solution methods. Mater. Sci. Eng. B 2000, 76, 145-155. [CrossRef] 
20. El-Farh, L.; Massot, M.; Lemal, M.; Julien, C. Physical properties and electrochemical features of lithium nickel-cobalt oxide cathode materials prepared at moderate temperature. J. Electroceram. 1999, 3, 425-432. [CrossRef]

21. Julien, C.; Nazri, G.A.; Rougier, A. Electrochemical performances of layered $\mathrm{LiM}_{1-\mathrm{y}} \mathrm{M}_{\mathrm{y}}^{\prime} \mathrm{O}_{2}(\mathrm{M}=\mathrm{Ni}, \mathrm{Co}$; $\left.\mathrm{M}^{\prime}=\mathrm{Mg}, \mathrm{Al}, \mathrm{B}\right)$ oxides in lithium batteries. Solid State Ion. 2000, 135, 121-130. [CrossRef]

22. Chen, J.; Wang, S.; Whittingham, M.S. Hydrothermal synthesis of cathode materials. J. Power Sources 2007, 174, 442-448. [CrossRef]

23. Zhang, X.; Jiang, W.J.; Zhu, X.P.; Mauger, A.; Lu, Q.; Julien, C.M. Aging of $\mathrm{LiNi}_{1 / 3} \mathrm{Mn}_{1 / 3} \mathrm{Co}_{1 / 3} \mathrm{O}_{2}$ cathode material upon exposure to $\mathrm{H}_{2}$ O. J. Power Sources 2011, 196, 5102-5108. [CrossRef]

24. Abdel-Ghany, A.; Zaghib, K.; Gendron, F.; Mauger, A.; Julien, C.M. Structural, magnetic and electrochemical properties of $\mathrm{LiNi}_{0.5} \mathrm{Mn}_{0.5} \mathrm{O}_{2}$ as positive electrode for Li-ion batteries. Electrochim. Acta 2007, 52, 4092-4100. [CrossRef]

25. Yamada, A.; Chung, S.C.; Hinokuma, K. Optimized $\mathrm{LiFePO}_{4}$ for lithium battery cathode. J. Electrochem. Soc. 2001, 148, A224-A229. [CrossRef]

26. Okubo, M.; Hosono, E.; Kim, J.; Enomoto, M.; Kojima, N.; Kudo, T.; Zhou, H.; Honma, I. Nanosize effect on high-rate Li-ion intercalation in $\mathrm{LiCoO}_{2}$ electrode. J. Am. Chem. Soc. 2007, 129, 7444-7452. [CrossRef] [PubMed]

27. Castro-Couceiro, A.; Castro-Garcia, S.; Senaris-Rodriguez, M.A.; Soulette, F.; Julien, C. Effects of the aluminum doping on the microstructure and morphology of $\mathrm{LiNi}_{0.5} \mathrm{Co}_{0.5} \mathrm{O}_{2}$ oxides. Ionics 2002, 8, $192-200$. [CrossRef]

28. Brochu, F.; Guerfi, A.; Trottier, J.; Kopec, M.; Mauger, A.; Groult, H.; Julien, C.M.; Zaghib, K. Structure and electrochemistry of scaling nano $\mathrm{C}-\mathrm{LiFePO}_{4}$ synthesized by hydrothermal route: Complexing agent effect. J. Power Sources 2012, 214, 1-6. [CrossRef]

29. Lee, K.S.; Myung, S.T.; Prakash, J.; Yashiro, H.; Sun, Y.K. Optimization of microwave synthesis of $\mathrm{Li}\left(\mathrm{Ni}_{0.4} \mathrm{Co}_{0.2} \mathrm{Mn}_{0.4}\right) \mathrm{O}_{2}$ as a positive electrode material for lithium batteries. Electrochim. Acta 2008, 53, 3065-3074. [CrossRef]

30. Zhang, X.; Jiang, W.J.; Mauger, A.; Li, Q.; Gendron, F.; Julien, C.M. Minimization of the cation mixing in $\mathrm{Li}_{1+\mathrm{x}}(\mathrm{NMC})_{1-\mathrm{x}} \mathrm{O}_{2}$ as cathode material. J. Power Sources 2010, 195, 1292-1301. [CrossRef]

31. Chen, Z.; Wang, J.; Chao, D.; Baikie, T.; Bai, L.; Chen, S.; Zhao, Y.; Sum, T.C.; Lin, J.; Shen, Z. Hierarchical porous $\mathrm{LiNi}_{1 / 3} \mathrm{Co}_{1 / 3} \mathrm{Mn}_{1 / 3} \mathrm{O}_{2}$ nano-micro spherical cathode material: Minimizes cation mixing and improved $\mathrm{Li}^{+}$mobility for enhanced electrochemical performance. Sci. Rep. 2016, 6, 25771. [CrossRef] [PubMed]

32. Liao, P.Y.; Duh, J.G.; Sheen, S.R. Effect on Mn content on the microstructure and electrochemical performance of $\mathrm{LiNi}_{0.75-\mathrm{x}} \mathrm{Co}_{0.25} \mathrm{Mn}_{\mathrm{x}} \mathrm{O}_{2}$ cathode materials. J. Electrochem. Soc. 2005, 152, A1695-A1700. [CrossRef]

33. Kang, K.; Meng, Y.S.; Bréger, J.; Grey, C.P.; Ceder, G. Electrodes with high power and high capacity for rechargeable lithium batteries. Science 2006, 311, 977-980. [CrossRef] [PubMed]

34. Oh, S.W.; Park, S.H.; Park, C.W.; Sun, Y.K. Structural and electrochemical properties of layered $\mathrm{Li}\left(\mathrm{Ni}_{0.5} \mathrm{Mn}_{0.5}\right)_{1-\mathrm{x}} \mathrm{Co}_{\mathrm{x}} \mathrm{O}_{2}$ positive materials synthesized by ultrasonic spray pyrolysis method. Solid State Ion. 2004, 171, 167-172. [CrossRef]

35. Tran, N.; Croguenec, L.; Jordy, C.; Biensan, P.; Delmas, C. Influence of the synthesis route on the electrochemical properties of $\mathrm{LiNi}_{0.425} \mathrm{Mn}_{0.425} \mathrm{Co}_{0.15} \mathrm{O}_{2}$. Solid State Ion. 2005, 176, 1539-1547. [CrossRef]

36. Ngala, J.K.; Chernova, N.A.; Ma, M.; Mamak, M.; Zavalij, P.Y.; Whittingham, M.S. The synthesis, characterization and electrochemical behavior of the layered $\mathrm{LiNi}_{0.4} \mathrm{Mn}_{0.4} \mathrm{Co}_{0.2} \mathrm{O}_{2}$ compound. J. Mater. Chem. 2004, 14, 214-220. [CrossRef]

37. Tsai, Y.W.; Lee, J.F.; Liu, D.G.; Hwang, B.J. In-situ X-ray absorption spectroscopy investigations of a layered $\mathrm{LiNi}_{0.65} \mathrm{Co}_{0.25} \mathrm{Mn}_{0.1} \mathrm{O}_{2}$ cathode material for rechargeable lithium batteries. J. Mater. Chem. 2004, 14, 958-965. [CrossRef]

38. Mauger, A.; Gendron, F.; Julien, C.M. Magnetic properties of $\mathrm{Li}_{\mathrm{x}} \mathrm{Ni}_{\mathrm{y}} \mathrm{Mn}_{\mathrm{y}} \mathrm{Co}_{1-2 \mathrm{y}} \mathrm{O}_{2}(0.2 \leqslant 1-2 y \leqslant 0.5,0 \leqslant x \leqslant 1)$. J. Alloys Compd. 2012, 520, 42-51. [CrossRef]

39. Julien, C.M.; Ait-Salah, A.; Mauger, A.; Gendron, F. Magnetic properties of intercalation compounds as positive electrodes for Li-ion batteries. Ionics 2006, 12, 21-32. [CrossRef] 
40. Samarasinghab, P.; Tran-Nguyen, D.H.; Behma, M.; Wijayasinghe, A. $\mathrm{LiNi}_{1 / 3} \mathrm{Mn}_{1 / 3} \mathrm{Co}_{1 / 3} \mathrm{O}_{2}$ synthesized by the Pechini method for the positive electrode in Li-ion batteries: Material characteristics and electrochemical behaviour. Electrochim. Acta 2008, 53, 7995-8000. [CrossRef]

41. Myung, S.T.; Komaba, S.; Kurihara, K.; Hosoya, K.; Kumagai, N.; Sun, Y.K.; Nakai, I.; Yonemura, M.; Kamiyama, T. Synthesis of $\mathrm{Li}\left(\left(\mathrm{Ni}_{0.5} \mathrm{Mn}_{0.5}\right)_{1-\mathrm{x}} \mathrm{Li}_{\mathrm{x}}\right) \mathrm{O}_{2}$ by emulsion drying method and impact of excess $\mathrm{Li}$ on structural and electrochemical properties. Chem. Mater. 2006, 18, 1658-1666. [CrossRef]

42. Xu, B.; Qian, D.; Wang, Z.; Meng, Y.S. Recent progress in cathode materials research for advanced lithium ion batteries. Mater. Sci. Eng. R 2012, 73, 51-65. [CrossRef]

43. Shaju, K.M.; Subba Rao, G.V.; Chowdari, B.V.R. Li-ion kinetics and polarization effect on the electrochemical performance of $\mathrm{Li}\left(\mathrm{Ni}_{1 / 2} \mathrm{Mn}_{1 / 2}\right) \mathrm{O}_{2}$. Electrochim. Acta 2004, 49, 1565-1576. [CrossRef]

44. Julien, C.; Michael, S.S.; Ziolkiewicz, S. Structural and electrochemical properties of $\mathrm{LiNi}_{0.3} \mathrm{Co}_{0.7} \mathrm{O}_{2}$ synthesized by different low-temperature techniques. Intl. J. Inorg. Mater. 1999, 1, 29-37. [CrossRef]

45. Ben-Kamel, K.; Ben-Amor, G.; Amdouni, N.; Mauger, A.; Groult, H.; Julien, C.M. $\mathrm{LiNi}_{0.33+\delta} \mathrm{Mn}_{0.33+\delta} \mathrm{Co}_{0.33-2 \delta} \mathrm{O}_{2}(0.025 \leqslant \delta \leqslant 0.075)$ cathode materials for Li-ion batteries: Local structure. ECS Trans. 2011, 35, 129-134.

46. Ben Kamel, K.; Amdouni, N.; Trottier, J.; Zaghib, K.; Mauger, A.; Groult, H.; Julien, C.M. $\mathrm{LiNi}_{0.33+\delta} \mathrm{Mn}_{0.33+\delta} \mathrm{Co}_{0.33-2 \delta} \mathrm{O}_{2}(0.0 \leqslant \delta \leqslant 0.075)$ cathode materials for Li-ion batteries: Electrochemical features. ECS Trans. 2011, 35, 135-139.

47. Ye, D.L.; Wang, L.Z. $\mathrm{Li}_{2} \mathrm{MnO}_{3}$ based Li-rich cathode materials: Towards a better tomorrow of high energy lithium ion batteries. Mater. Technol. Adv. Perform. Mater. 2014, 29, A59-A69.

48. Yu, H.; Zhou, H. High-energy cathode materials $\left(\mathrm{Li}_{2} \mathrm{MnO}_{3}-\mathrm{LiMO}_{2}\right)$ for lithium-ion batteries. J. Phys. Chem. Lett. 2013, 4, 1268-1280. [CrossRef] [PubMed]

49. Lu, Z.; Dahn, J.R. Structure and electrochemistry of layered $\operatorname{Li}\left(\mathrm{Cr}_{\mathrm{x}} \mathrm{Li}_{(1 / 3-\mathrm{x} / 3)} \mathrm{Mn}_{(2 / 3-2 x / 3)}\right) \mathrm{O}_{2}$. J. Electrochem. Soc. 2002, 149, A1454-A1459. [CrossRef]

50. Deng, Z.; Manthiram, A. Influence of cationic substitutions on the oxygen loss and reversible capacity of lithium-rich layered oxide cathodes. J. Phys. Chem. C 2011, 115, 7097-7103. [CrossRef]

51. Muhammad, S.; Kim, H.; Kim, Y.; Kim, D.; Song, J.H.; Yoon, J.; Park, J.H.; Ahn, S.J.; Kang, S.H.; Thakeray, M.M.; et al. Evidence of reversible oxygen participation in anomalously high capacity Li- and Mn-rich cathodes for Li-ion batteries. Nano Energy 2016, 21, 172-184. [CrossRef]

52. Lee, D.K.; Park, S.H.; Amine, K.; Bang, H.J.; Parakash, J.; Sun, Y.K. High capacity $\operatorname{Li}\left(\operatorname{Li}_{0.2} \mathrm{Ni}_{0.2} \mathrm{Mn}_{0.6}\right) \mathrm{O}_{2}$ cathode materials via a carbonate co-precipitation method. J. Power Sources 2006, 162, 1346-1350. [CrossRef]

53. Liu, Y.J.; Liu, S.B.; Wang, Y.P.; Chen, L.; Chen, X.H. Effect of $\mathrm{MnO}_{2}$ modification on electrochemical performance of $\mathrm{LiNi}_{0.2} \mathrm{Li}_{0.2} \mathrm{Mn}_{0.6} \mathrm{O}_{2}$ layered solid solution cathode. J. Power Sources 2013, 222, 455-460. [CrossRef]

54. Zhao, Y.; Xia, M.; Hu, X.; Zhao, Z.; Wang, Y.; Lv, Z. Effects of Sn doping on the structural and electrochemical properties of $\mathrm{Li}_{1.2} \mathrm{Ni}_{0.2} \mathrm{Mn}_{0.6} \mathrm{O}_{2}$ Li-rich cathode materials. Electrochim. Acta 2015, 174, 1167-1174. [CrossRef]

55. Lu, Z.; MacNeil, D.; Dahn, J.R. Layered cathode materials $\operatorname{Li}\left(\mathrm{Ni}_{\mathrm{x}} \mathrm{Li}_{(1 / 3-2 \mathrm{x} / 3)} \mathrm{Mn}_{(2 / 3-\mathrm{x} / 3)}\right) \mathrm{O}_{2}$ for lithium-ion batteries. Electrochem. Solid-State Lett. 2001, 4, A191-A194. [CrossRef]

56. Lu, Z.; Dahn, J.R. Understanding the anomalous capacity of $\mathrm{Li}\left(\mathrm{Ni}_{\mathrm{x}} \mathrm{Li}_{(1 / 3-2 x / 3)} \mathrm{Mn}_{(2 / 3-\mathrm{x} / 3)}\right) \mathrm{O}_{2}$ cells using in situ X-ray diffraction and electrochemical studies. J. Electrochem. Soc. 2002, 149, A815-A822. [CrossRef]

57. Lu, Z.; Beaulieu, L.; Donaberger, R.; Thomas, C.; Dahn, J.R. Synthesis, structure, and electrochemical behavior of $\mathrm{Li}\left(\mathrm{Ni}_{\mathrm{x}} \mathrm{Li}_{(1 / 3-2 \mathrm{x} / 3)} \mathrm{Mn}_{(2 / 3-\mathrm{x} / 3)}\right) \mathrm{O}_{2}$. J. Electrochem. Soc. 2002, 149, A778-A791. [CrossRef]

58. Boulineau, A.; Simonin, L.; Colin, J.-F.; Bourbon, C.; Patoux, S. First Evidence of manganese-nickel segregation and densification upon cycling in Li-rich layered oxides for lithium batteries. Nano Lett. 2013, 13, 3857-3863. [CrossRef] [PubMed]

59. McCalla, E.; Rowe, A.W.; Camardese, J.; Dahn, J.R. The role of metal site vacancies in promoting Li-Mn-Ni-O layered solid solutions. Chem. Mater. 2013, 25, 2716-2721. [CrossRef]

60. Yu, H.; Ishikawa, R.; So, Y.G.; Shibata, N.; Kudo, T.; Zhou, H.; Ikuhara, Y. Direct atomic-resolution observation of two phases in the $\mathrm{Li}_{1.2} \mathrm{Mn}_{0.567} \mathrm{Ni}_{0.166} \mathrm{Co}_{0.067} \mathrm{O}_{2}$ cathode material for lithium-ion batteries. Angew. Chem. Int. Ed. 2013, 52, 5969-5973. [CrossRef] [PubMed]

61. Hy, S.; Felix, F.; Rick, J.; Su, W.-N.; Hwang, B.J. Direct in situ observation of Li2O evolution on Li-rich high-capacity cathode material, $\mathrm{Li}\left(\mathrm{Ni}_{\mathrm{x}} \mathrm{Li}_{(1 / 3-2 \mathrm{x} / 3)} \mathrm{Mn}_{(2 / 3-\mathrm{x} / 3)}\right) \mathrm{O}_{2}(0 \leqslant \mathrm{x} \leqslant 0.5)$. J. Am. Chem. Soc. 2014, 136, 999-1007. [CrossRef] [PubMed] 
62. Wu, F.; Li, N.; Su, Y.; Shou, H.; Bao, L.; Yang, W.; Zhang, L.; An, R.; Chen, S. Spinel/layered heterostructured cathode material for high-capacity and high-rate Li-ion batteries. Adv. Mater. 2013, 25, 3722-3726. [CrossRef] [PubMed]

63. Yu, H.; Kim, H.; Wang, Y.; He, P. High-energy 'composite' layered manganese-rich cathode materials via controlling $\mathrm{Li}_{2} \mathrm{MnO}_{3}$ phase activation for lithium-ion batteries. Phys. Chem. Chem. Phys. 2012, 14, 6584-6595. [CrossRef] [PubMed]

64. Rowe, W.; Dahn, J.R. Positive Electrode Materials in the Li-Mn-Ni-O System exhibiting anomalous capacity growth during extended cycling. J. Electrochem. Soc. 2014, 161, A308-A317. [CrossRef]

65. Gu, M.; Belharouak, I.; Zheng, J.; Wu, H.; Xiao, J.; Genc, A.; Amine, K.; Thevuthasan, S.; Baer, D.R.; Zhang, J.-G.; et al. Formation of the spinel phase in the layered composite cathode used in Li-ion batteries. ACS Nano 2013, 7, 760-767. [CrossRef] [PubMed]

66. Song, B.; Lai, M.O.; Liu, Z.; Liu, H.; Lu, L. Graphene-based surface modification on layered Li-rich cathode for high-performance Li-ion batteries. J. Mater. Chem A 2013, 1, 9954-9965. [CrossRef]

67. Song, B.; Liu, H.; Liu, Z.; Xiao, P.; Lai, M.O.; Lu, L. High rate capability caused by surface cubic spinels in Li-rich layer-structured cathodes for Li-ion batteries. Sci. Rep. 2013, 3, 3094. [CrossRef] [PubMed]

(C) 2016 by the authors; licensee MDPI, Basel, Switzerland. This article is an open access article distributed under the terms and conditions of the Creative Commons Attribution (CC-BY) license (http://creativecommons.org/licenses/by/4.0/). 